\title{
Mechanisms Associated with Large Daily Rainfall Events in Northeast Brazil
}

\author{
Brant Liebmann, ${ }^{*}$ George N. Kiladis, ${ }^{+}$Dave Allured, ${ }^{*}$ Carolina S. Vera, ${ }^{*}$ \\ CHARlES JONES, @ LEILA M. V. CARVALHO,\& IlEANA BladÉ,** \\ AND PAUla L. M. GONZÁLES\# \\ * NOAA/Earth System Research Laboratory, and CIRES Climate Diagnostics Center, Boulder, Colorado \\ ${ }^{+}$Physical Sciences Division, NOAA/Earth System Research Laboratory, Boulder, Colorado \\ \# CIMA/UBA-CONICET, Department of Atmospheric and Ocean Sciences/FCEyN/UBA, Buenos Aires, Argentina \\ ${ }^{\circledR}$ Institute for Computational Earth System Science, University of California, Santa Barbara, Santa Barbara, California \\ \& Department of Geography and Institute for Computational Earth System Science, University of California, Santa Barbara, \\ Santa Barbara, California, and Department of Atmospheric Sciences, University of São Paulo, São Paulo, Brazil \\ ** Departament d'Astronomia i Meteorologia, Universitat de Barcelona, Barcelona, Spain
}

(Manuscript received 1 October 2009, in final form 3 August 2010)

\begin{abstract}
The mechanisms resulting in large daily rainfall events in Northeast Brazil are analyzed using data filtering to exclude periods longer than 30 days. Composites of circulation fields that include all independent events do not reveal any obvious forcing mechanisms as multiple patterns contribute to Northeast Brazil precipitation variability. To isolate coherent patterns, subsets of events are selected based on anomalies that precede the Northeast Brazil precipitation events at different locations. The results indicate that at $10^{\circ} \mathrm{S}, 40^{\circ} \mathrm{W}$, the area of lowest annual rainfall in Brazil, precipitation occurs mainly in association with trailing midlatitude synoptic wave trains originating in either hemisphere. Closer to the equator at $5^{\circ} \mathrm{S}, 37.5^{\circ} \mathrm{W}$, an additional convection precursor is found to the west, with a spatial structure consistent with that of a Kelvin wave. Although these two sites are located within only several hundred kilometers of each other and the midlatitude patterns that induce precipitation appear to be quite similar, the dates on which large precipitation anomalies occur at each location are almost entirely independent, pointing to separate forcing mechanisms.
\end{abstract}

\section{Introduction}

The easternmost part of Brazil, which approximates the area known as Northeast Brazil, is the driest part of that country and also the poorest. Figure 1 (data are described in section 2) shows the large contrast in annual precipitation totals between this region and the Amazon Basin to the west. The low rainfall, coupled with a lack of access to the copious Amazon Basin discharge, makes Northeast Brazil one of the most vulnerable regions on earth to variations in seasonal total rainfall, which are substantial. Kousky (1979) found that the interannual range of precipitation in the most arid parts of northeast Brazil exceeds $40 \%$ of the climatological total. As an example that provides perspective to this finding, at the location of minimum precipitation (located at $10^{\circ} \mathrm{S}$, $40^{\circ} \mathrm{W}$ in our dataset) the average annual precipitation is

Corresponding author address: Brant Liebmann, CIRES Climate Diagnostics Center, Campus Box 216, Boulder, CO 80309-0216.

E-mail: brant.liebmann@noaa.gov
$530 \mathrm{~mm}$ per year with a standard deviation of $97 \mathrm{~mm}$, whereas the Amazon Basin at $0^{\circ}, 65^{\circ} \mathrm{W}$ averages $2450 \mathrm{~mm}$ with a standard deviation of $80 \mathrm{~mm}$.

Further increasing vulnerability, almost all rainfall in Northeast Brazil falls in a relatively short season (e.g., Ramos 1975; Hastenrath and Heller 1977; Kousky 1979; Uvo et al. 1998). Figure 2 shows monthly climatologies at the precipitation minimum $\left(10^{\circ} \mathrm{S}, 40^{\circ} \mathrm{W}\right.$; hereafter referred to as the "interior" point) and along the coast $\left(5^{\circ} \mathrm{S}, 37.5^{\circ} \mathrm{W}\right.$; hereafter referred to as the "coastal" point). Both these areas receive less than $50 \mathrm{~mm}$ per month over May-November and July-December, respectively. March is the wettest month at both locations, but the wet season begins and ends earlier at the interior point than near the coast.

The wet season in Northeast Brazil corresponds to the time of southernmost advance of the warm near-equatorial Atlantic sea surface temperatures (SSTs) and of the overlying low pressure trough in which the intertropical convergence zone (ITCZ) is embedded (Hastenrath and Heller 1977; Hastenrath and Greischar 1993a; Uvo et al. 


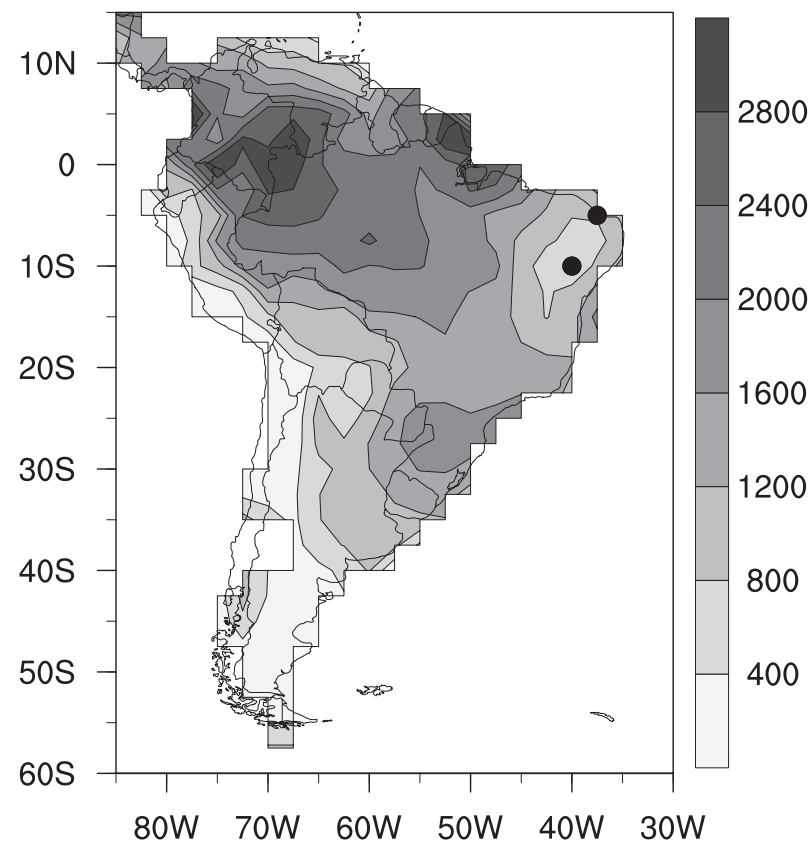

FIG. 1. Average annual total precipitation for 1979-2005 (mm) at $2.5^{\circ}$ resolution. Lines indicate perimeter of rainfall data coverage. Dots at $10^{\circ} \mathrm{S}, 40^{\circ} \mathrm{W}$ and $5^{\circ} \mathrm{S}, 37.5^{\circ} \mathrm{W}$-referred to in text as the "interior" and "coastal" points, respectively—indicate base points for detailed analyses.

1998; Kucharski et al. 2008). In years in which SST is anomalously warm south of the equator and cold in the north, the ITCZ extends farther south than usual and Northeast Brazil rainfall is enhanced (e.g., Hastenrath and Greischar 1993a; Uvo et al. 1998). Consistent with this idea, Moura and Shukla (1981) explained severe drought in Northeast Brazil by arguing that the presence of anomalously warm SSTs north of the equator causes a northward displacement of the ITCZ, which results in upward motion north of the equator and compensating subsidence over Northeast Brazil.

The model developed by Hastenrath and others of an Atlantic ITCZ that responds to SST anomalies is quite useful, as it provides both an understanding of the variability in Northeast Brazil and a method to predict seasonal precipitation. Indeed, the displacement of the ITCZ is responsible for a large fraction of annual precipitation in this region (Xavier et al. 2000). As noted by several investigators, however, the total seasonal precipitation over Northeast Brazil is made up of discrete events (e.g., Ramos 1975; Kousky 1979; De Souza et al. 2005; Rao et al. 2007). We illustrate the discrete nature of the rainfall by considering the stations near the coastal point, located within the region studied by Hastenrath (1990) and Hastenrath and Greischar (1993a), and near the interior point, an area not covered by those studies. During March-April 1985, the wettest season

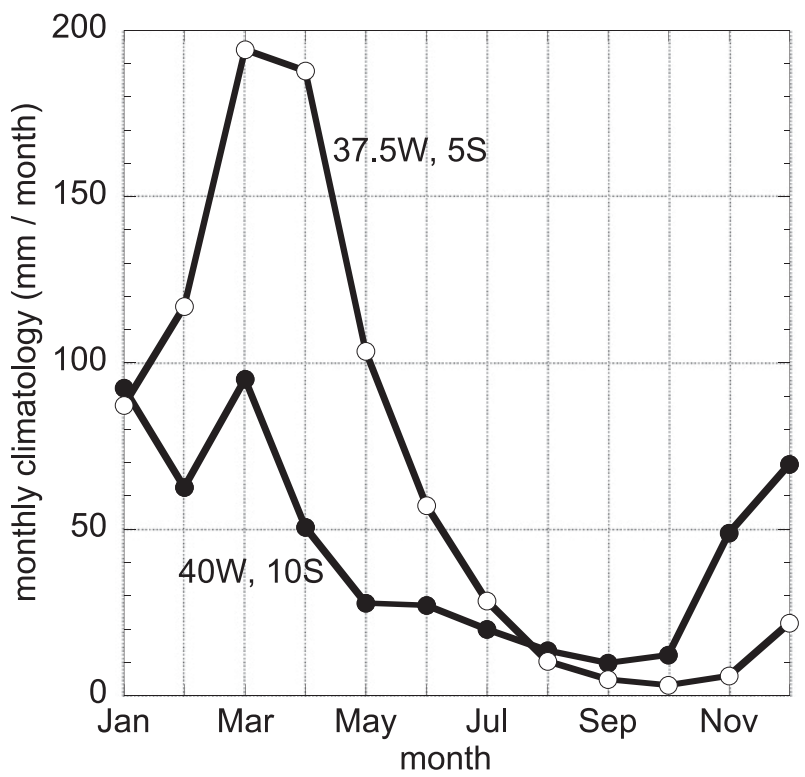

FIG. 2. Monthly climatology of total precipitation for the $2.5^{\circ}$ grid box at the interior (filled circles) and coastal (open circles) grid points.

of the 1979-2005 period included in this study, stations near the coastal point were dry, on average, $41 \%$ of days, while overall $60 \%$ of stations were dry on a given day during those months. In the interior, $85 \%$ of stations, on average, were dry on a given day in February and March.

These findings are consistent with those of Ramos (1975), who concluded that about six to eight precipitation events yield most of the annual rainfall in Northeast Brazil, and with Moron et al. (2007), who counted days with precipitation during the wet season in that region and found most stations had fewer than 35. Ramos also found that the disturbances associated with these events move westward at about the same speed as the lower tropospheric wind, and more slowly than one would expect if they were wavelike tropical disturbances. Kousky (1979) noted that these disturbances also moved northward at about the same speed and argued that this progression could indicate an extratropical origin. Kousky (1979) and Kousky and Ferreira (1981) documented northwardpropagating midlatitude cold fronts, or their remains, as the cause of discrete precipitation events in Northeast Brazil.

Low-latitude fronts, at times reaching as far north as Amazonia, are a well-documented feature of South America in all seasons (e.g., Kousky and Ferreira 1981; Garreaud 2000; Vera and Vigliarolo 2000). At equatorial latitudes, these fronts are mainly manifested in the pressure and wind fields (Garreaud and Wallace 1998; Rickenbach et al. 2002), with only weak temperature 
and moisture signals. Over Northeast Brazil, Kousky (1979) found some agreement between the frequency of occurrence of frontal boundaries and annual rainfall and speculated that precipitation depends more on the character of the fronts than on their number. For example, slowly moving fronts, possibly associated with equatorial wave development, are likely associated with larger precipitation amounts.

The spatial coherence of precipitation in Northeast Brazil is low (Kousky and Chu 1978; Kousky 1979; Silva et al. 2006; Moron et al. 2007), likely due in part to variations in topography (Silva et al. 2006). We can quantify the substantial regional variability of wet season precipitation by noting, for instance, that there is only a 0.45 correlation of November-June precipitation between the coastal and interior grid points. Correlations between individual stations at daily time scales fall to near zero beyond $100 \mathrm{~km}$ (Moron et al. 2007).

The purpose of the work presented here is to gain further insight into the causes of high-frequency precipitation events in Northeast Brazil. Although Kousky (1979) identified the remains of northward-propagating fronts as being associated with precipitation in this region, he did not document the temporal and spatial structure of these disturbances in detail. Moreover, there are likely other kinds of perturbations that can induce precipitation in this region, such as fronts originating in the Northern Hemisphere (Molion and Bernardo 2002). Convectively coupled Kelvin waves propagating along the equator (Wang and Fu 2007; Liebmann et al. 2009) some of which originate as pressure surges in central South America forced by Rossby wave activity over the South Pacific (Liebmann et al. 2009) — may also play a role in triggering rainfall in Northeast Brazil. In view of the low spatial coherence of precipitation in this region, it seems appropriate to examine the forcing mechanisms separately for the interior and coastal regions.

\section{Data}

The following analysis covers the period 1979-2005. The starting date was chosen because, after a long period of missing data, a nearly continuous record of outgoing longwave radiation (OLR) begins in January 1979. Missing OLR data are filled by spatial and temporal interpolation (Liebmann and Smith 1996). Height and wind fields are obtained from the National Centers for Environmental Prediction (NCEP)-National Center for Atmospheric Research (NCAR) Reanalysis I (Kalnay et al. 1996). Streamfunction is computed from the wind fields using spherical harmonic routines. The gridded precipitation dataset used in the study is described in Liebmann and Allured (2005), but it has been updated since initial publication. The resolution is $2.5^{\circ}$ in latitude and longitude. Stations within $1.875^{\circ}$ of a grid point are included in the gridpoint average. We note that the number of available station records has increased since the earlier studies of precipitation in Northeast Brazil. For example, Hastenrath and Greischar (1993b) employed records from only 27 stations to describe Northeast Brazil rainfall. In contrast, the values of our coastal and interior grid points represent averages of 390 and 293 station records, respectively (although few individual records are complete).

All time series used in this study have been high-pass filtered to remove periods longer than 30 days. The purpose of the filter is to exclude temporal variations on time scales of the Madden-Julian oscillation (MJO; Madden and Julian 1994), which is known to influence Northeast Brazil precipitation (e.g., Carvalho et al. 2004; Jones et al. 2004; De Souza and Ambrizzi 2006), while also conveniently removing the seasonal cycle and interannual variability. The Lanczos filter (Duchon 1979) uses 119 weights; thus, the filtered OLR record starts on 1 March 1979.

\section{Results}

All results presented here are based on anomalies of filtered precipitation in Northeast Brazil at selected base points. These results yield only marginally cleaner signals than those obtained using OLR and so can be assumed to be representative of convective events. While anomalies are determined using all available data (i.e., without regard to any particular season), there is a strong clustering of events with season. For example, Fig. 3, which shows the count by month of daily events at least two standard deviations above the residual filtered mean, reveals that most of the events near the coast occur between January and May, whereas those in the interior take place mostly between November and April. There is a general month-by-month correspondence between the count of two-standard-deviation precipitation extremes and climatological precipitation (Fig. 2).

\section{a. Interior grid point}

Interior rain events are chosen as those dates on which filtered precipitation anomalies are at least two standard deviations above the mean, with the condition that for events that exceed this threshold for more than 1 day, only the date with the largest anomaly is included. (The monthly climatological count shown in Fig. 3 includes all 345 dates above the threshold.) There are 260 independent events during the period 1979-2005, which matches the six to eight events per year estimated by Ramos (1975) as producing the bulk of the wet season total. The peak-day average anomaly is $9.8 \mathrm{~mm}$. This 


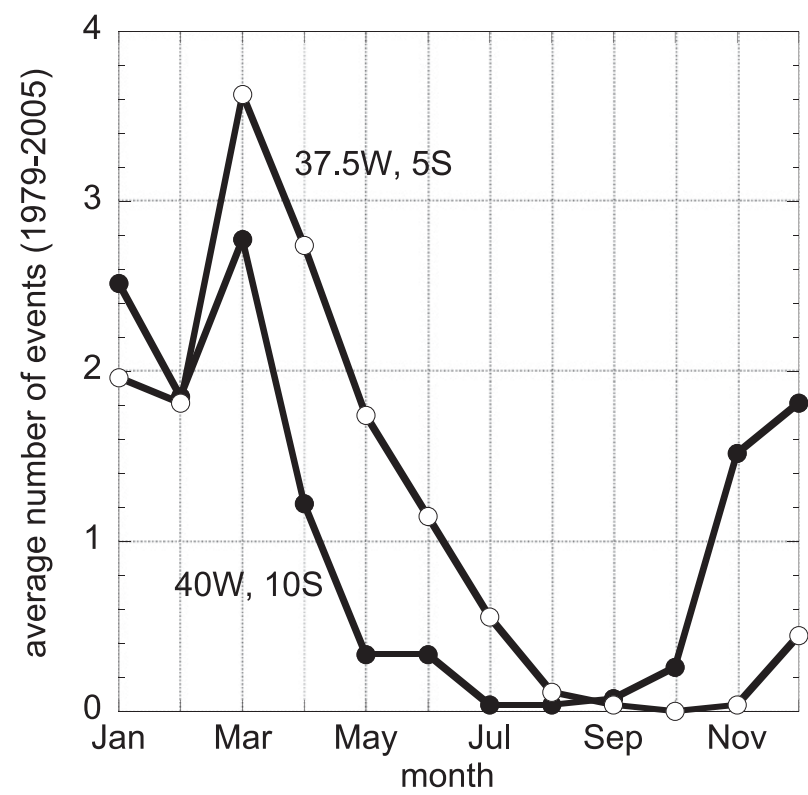

FIG. 3. Average number of daily precipitation occurrences of at least two standard deviations above the annual mean for each month at the interior (filled circles) and coastal (open circles) grid points. Standard deviations are calculated from annual data.

section shows lead and lag composites of these 260 events, or selected subsets of events.

To address the possibility that biases have been introduced by basing the composite analysis on filtered precipitation, the above calculation was repeated using unfiltered daily precipitation. That computation yielded 238 dates, 209 of which are in common with those obtained from filtered precipitation. Furthermore, the resulting composites are nearly identical to those presented here using dates based on filtered precipitation.

Figure 4 shows lead and lag composites of filtered OLR, 200-mb winds, and streamfunction anomalies for all independent rain events at the interior grid point. Negative OLR anomalies appear at the base point a day before the peak time (day -1$)$ and last for about 3 days, with little evidence of propagation. The $200-\mathrm{mb}$ circulation fields feature westward-propagating cyclones on days -4 and -3 that are somewhat symmetric about the equator, although the axis of symmetry appears to be south of the equator, near $10^{\circ} \mathrm{S}$. This symmetry breaks down by day -2 and the fields become increasingly asymmetric, with a tighter trough to the south. This trough is the only circulation feature that appears to be connected with the precipitation signal, consistent with Kousky and Gan's (1981) observation of enhanced cloudiness occurring in advance of an upper-level vortex over Northeast Brazil.

The local statistical significance of the wind vectors is estimated by a Monte Carlo approach. A total of 999 sample composites were generated from the same calendar dates used in the actual composite, except the years are mismatched (e.g., composites of wind in 1980 from the 1979 precipitation dates, etc.); within each year the order of dates remains unchanged to preserve the seasonal distribution of the samples. The composite wind speed is calculated for each sample at each grid point and compared to the speed of the actual composite. Vectors are plotted only if their speed exceeds $95 \%$ of the sample speeds. This technique is also applied to all subsequent figures.

The same dates are used to produce a composite of 850-mb winds, streamfunction, and temperature (Fig. 5). The only anomalies that stand out are westerly winds around the base grid point, which are associated with the pronounced cyclone to the south that precedes the maximum in precipitation. A cold anomaly also appears well to the south of the precipitation region and a sharp wind shift from westerly to northwesterly occurs around the base point, perhaps indicative of a frontal boundary.

A lower-level cyclonic anomaly and its attendant westerlies within the precipitation region would be consistent with a "Gill-type" response to off-equatorial diabatic heating (Gill 1980), but the low-level cyclone is already established and is much stronger 2 days prior to the precipitation peak than at day 0 (Fig. 5a). The fact that the most coherent circulation anomalies appear to precede the development of the OLR anomaly precludes any explanation in which the circulation pattern is a response to the diabatic heating, such as local instabilities similar to those that occur over the Amazon when largescale forcing is weak (e.g., Silva Dias et al. 2002). Furthermore, Northeast Brazil is an area with only episodic intense deep convection, unlike the heart of the South American monsoon region, where deep convection is common. Thus, the composites do not suggest any obvious manner by which the rainfall is forced.

In light of the studies of Kousky (1979) and Kousky and Gan (1981), which indicate that precipitation anomalies in Northeast Brazil are often forced by disturbances propagating into the region from the extratropics, and other studies suggesting a variety of mechanisms producing precipitation patterns over the region (e.g., Rao and Bonatti 1987), a more probable reason for the indistinct upper-level pattern in Fig. 4 is that this composite displays a blurred mixture of more than one precipitationproducing pattern. This hypothesis can be tested by employing the technique used in Liebmann et al. (2009) to separate the forcing of Kelvin wave activity over the Amazon into events that propagate into the region from the Pacific and events originating from fronts in the Southern Hemisphere.

Our technique for isolating disturbances emanating from different regions is simpler and, in this case at least, 
a)

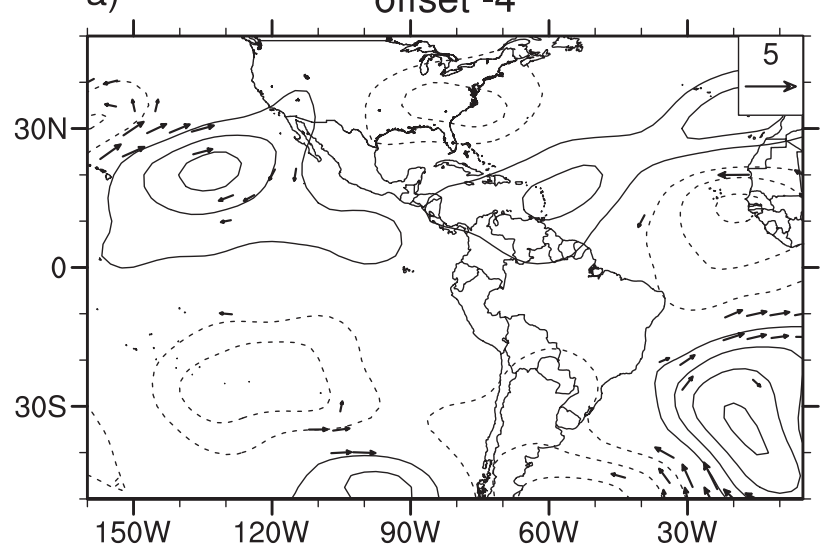

b)

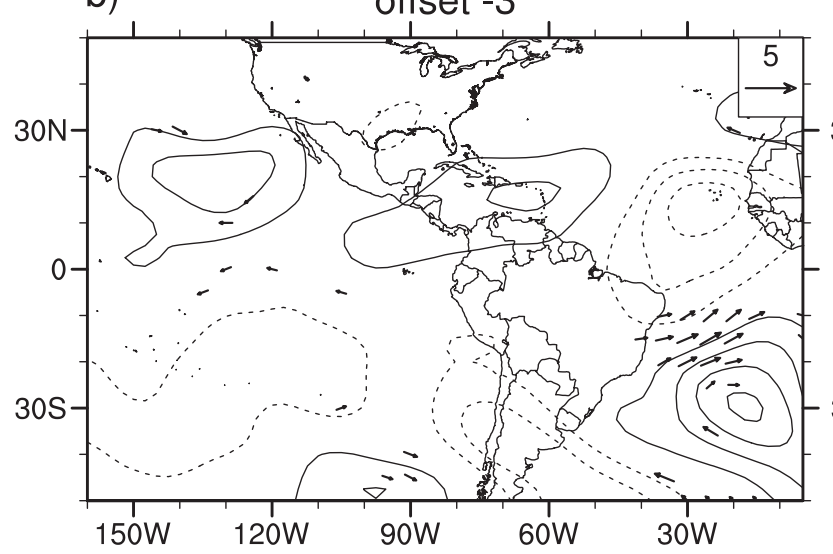

c)

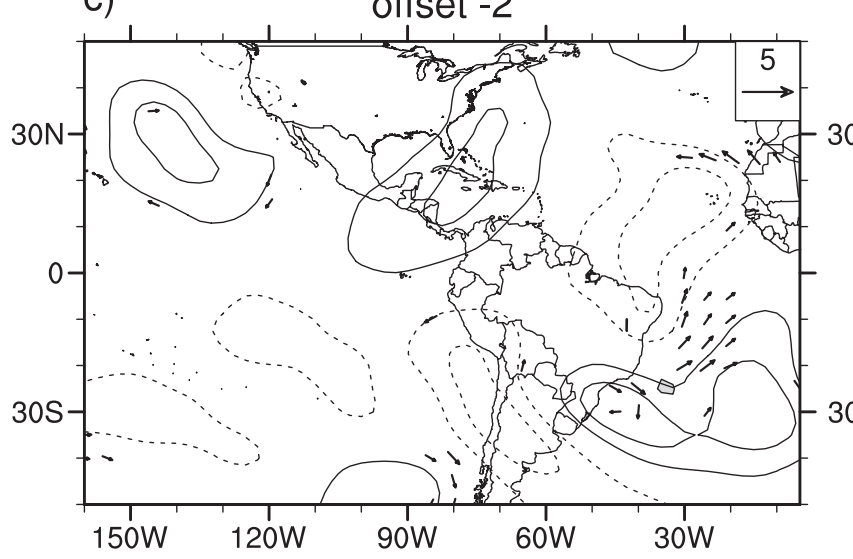

d)

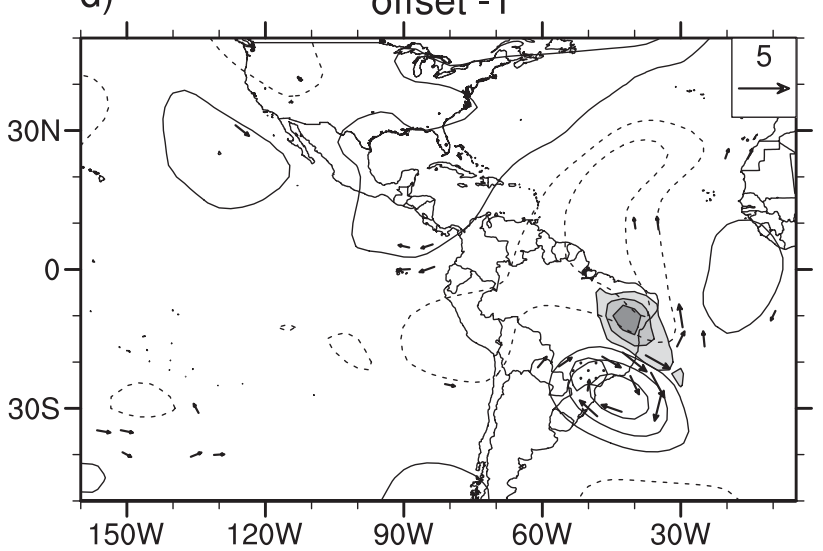

e) offset -1

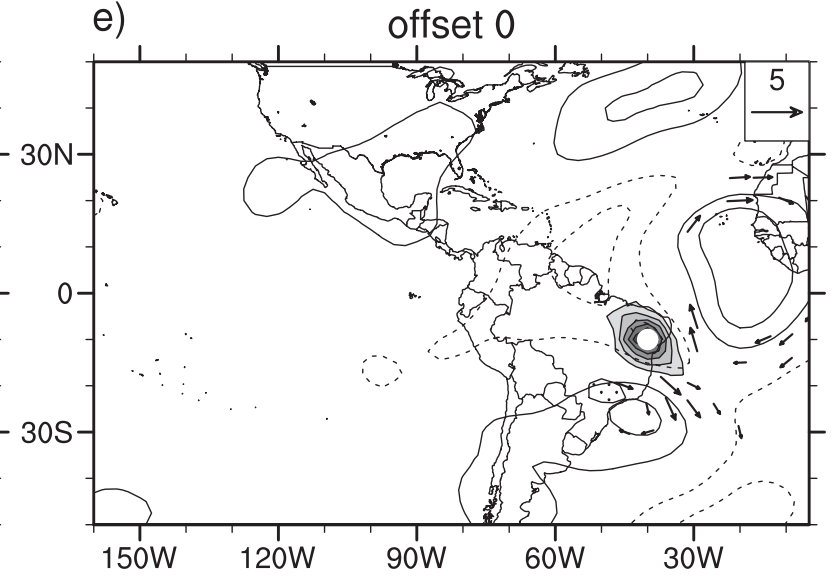

f)
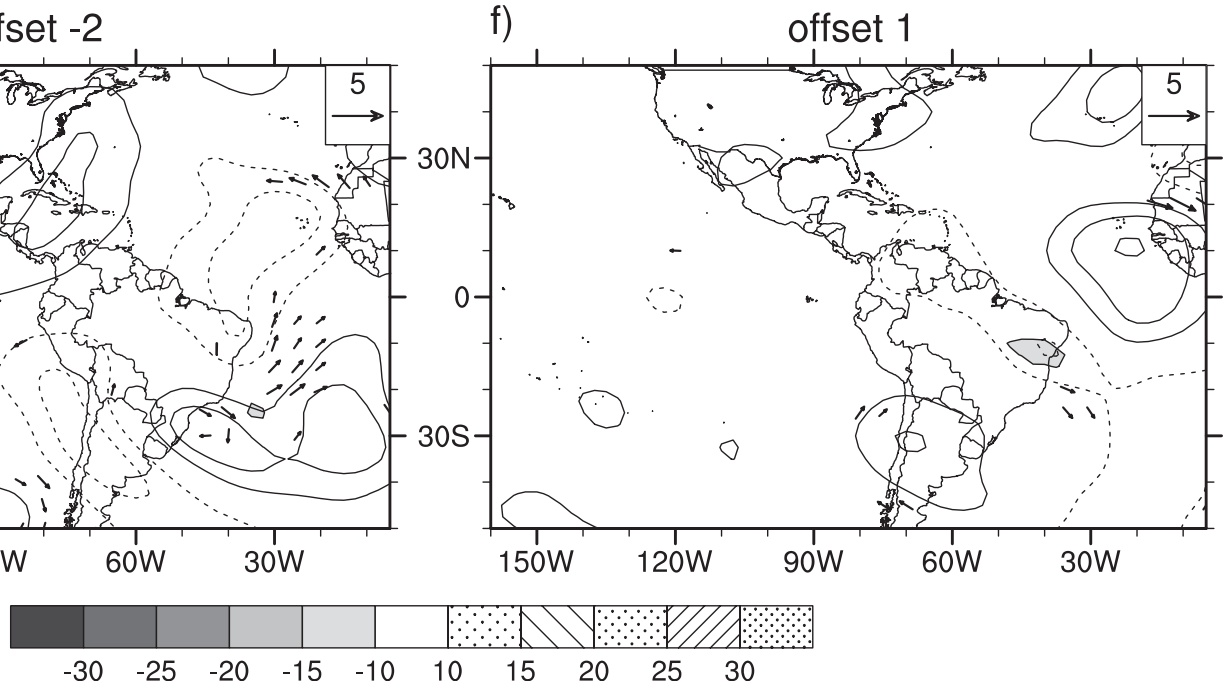

FIG. 4. Composite of 260 independent dates on which precipitation at the interior grid point was at least 2 standard deviations above the annual mean: offset (a) -4 , (b) -3 , (c) -2 , (d) -1 , (e) 0 , and (f) +1 days. Only days with largest value of multiday sequence above threshold are included. The white dot on the day-0 map indicates the location of the base point. Contours are 30-day high-pass filtered 200mb streamfunction anomalies with an interval of $7.5 \times 10^{5} \mathrm{~m}^{2} \mathrm{~s}^{-2}$, with the 0 contour omitted and negative contours dashed. Shading represents 30-day high-pass filtered OLR anomalies $\left(\mathrm{W} \mathrm{m}^{-2}\right)$, and vectors represent 30-day high-pass filtered wind anomalies $\left(\mathrm{m} \mathrm{s}^{-1}\right)$ at $200 \mathrm{mb}$. Wind vectors are plotted only if speed exceeds the upper fifth percentile of speeds computed from 999 random samples and is larger than $10 \%$ of reference vector (shown in upper right corner). 

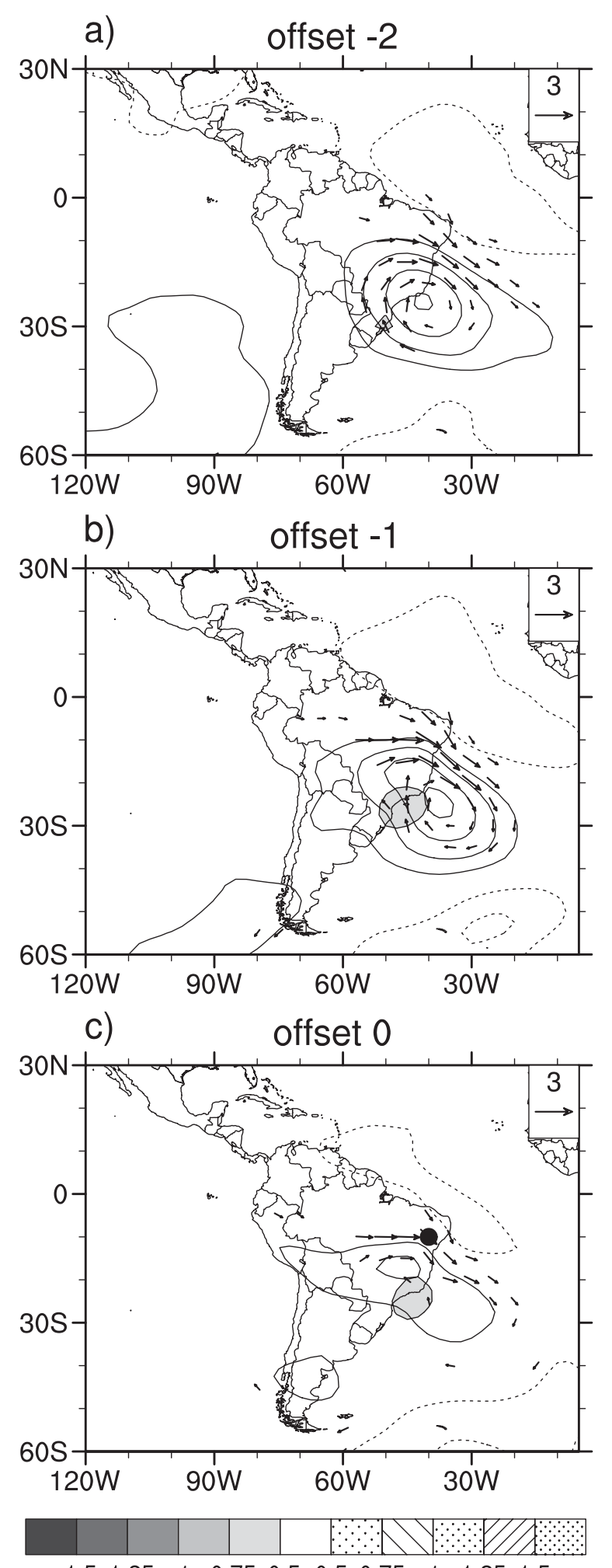

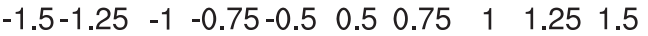

FIG. 5. As in Fig. 4, except plotted quantities are composites of $850-\mathrm{mb}$ wind, streamfunction, and temperature. Contour interval for streamfunction is $5.0 \times 10^{5} \mathrm{~m}^{2} \mathrm{~s}^{-2}$, with the 0 contour omitted and negative contours dashed. more effective than the traditional approach involving empirical orthogonal function (EOF) analysis. Initially, various forms of EOF analysis were applied to this problem but the results were difficult to reconcile with our synoptic understanding of rainfall in this region, gained from detailed inspection of many individual events. Guided by this experience and by examination of composite circulation maps for large precipitation anomalies that appeared to be physically realistic, the independent rain events (as defined above) were instead segregated into subsets according to various criteria. For the interior location, these criteria were developed by noting that many rain events were accompanied by large wave trains propagating into the region from either hemisphere.

Figure 6 shows a composite of the subset of events at the interior grid point that are preceded by $200-\mathrm{mb}$ southeasterly wind anomalies of at least one standard deviation at $27.5^{\circ} \mathrm{S}, 55^{\circ} \mathrm{W}$ on day -1 . The exact precursor point was determined through experimentation. The dates for all two-standard-deviation rain anomalies at the base point are cross-referenced with the precursor dates, the matches are found, and if there are sequential dates only the date with the largest base point anomaly is used. There are 52 days that meet both criteria (out of the original 260). Note that in this figure the streamfunction contour interval and the reference wind vector are both twice as large as those in Fig. 4. The composite features a readily identifiable pattern of a midlatitude-originating wave train propagating into Northeast Brazil from the southwest, while the Northern Hemisphere is almost featureless. Successive centers that develop downstream and decay upstream signify a northeastward-propagating group velocity, while the circulation anomaly centers themselves are nearly stationary.

The principal OLR anomaly in Fig. 6 is first evident over the ocean off the coast of Brazil on day -4 around the mean position of the oceanic South Atlantic convergence zone (SACZ; e.g., Carvalho et al. 2002). The anomaly expands along a northwest-southeast axis and moves northward, remaining along the leading edge of the upper-level trough, which is suggestive of midlatitude baroclinic wave dynamics.

The disturbances are reminiscent of the Rossby wave trains that propagate from the Southern Hemisphere midlatitudes into the vicinity of the South Atlantic convergence zone and force subseasonal precipitation there (e.g., Liebmann et al. 1999). They also bear a resemblance to the Rossby waves associated with pressure surges along the eastern side of the Andes that can trigger a Kelvin wave propagating along the equator (Liebmann et al. 2009). The quasi-stationary phase speeds identified in the present study, however, are in contrast with the rapid eastward phase speeds of the synoptic disturbances 
a)

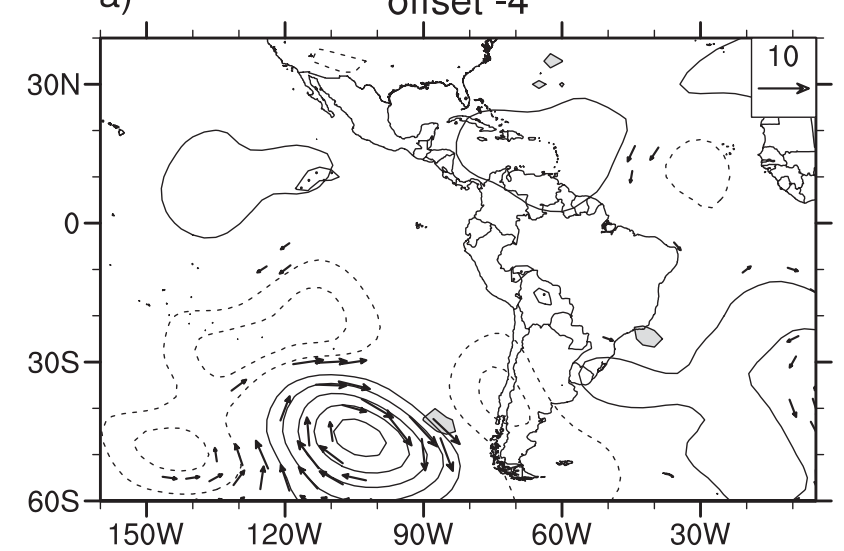

b)

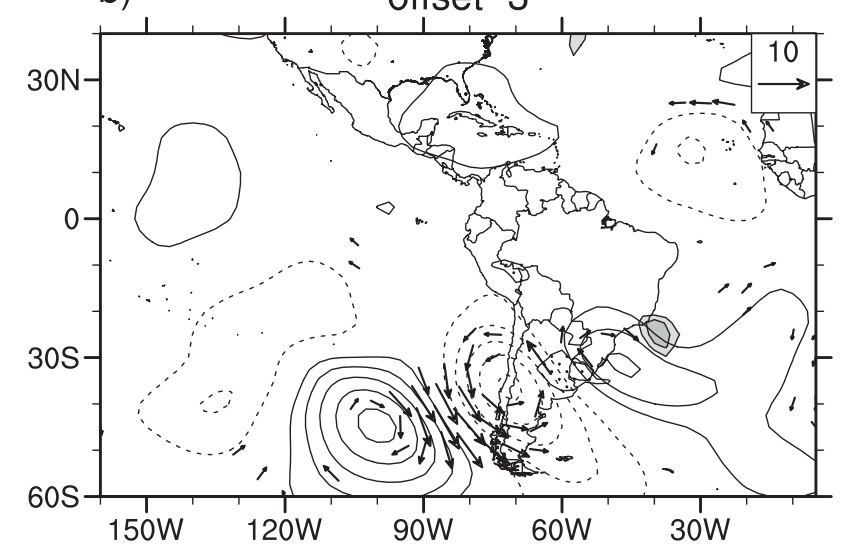

c) offset -4

offset -3

offset -2 d)

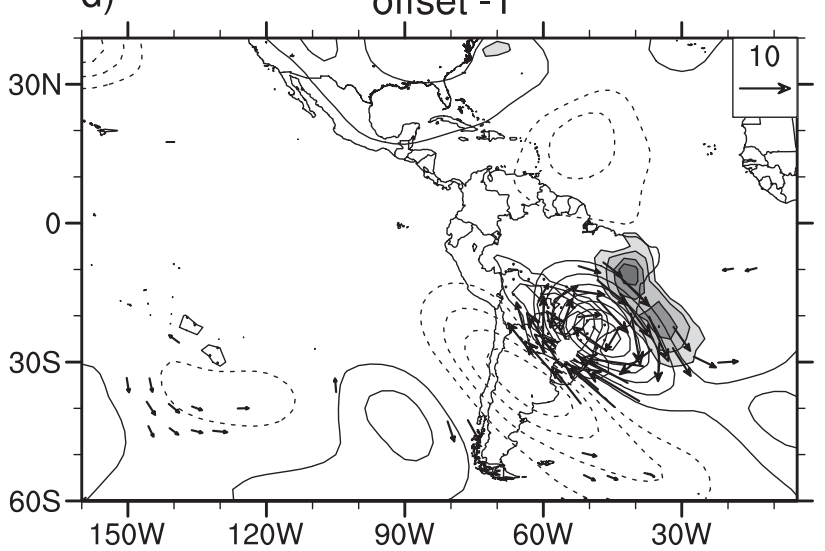

e)

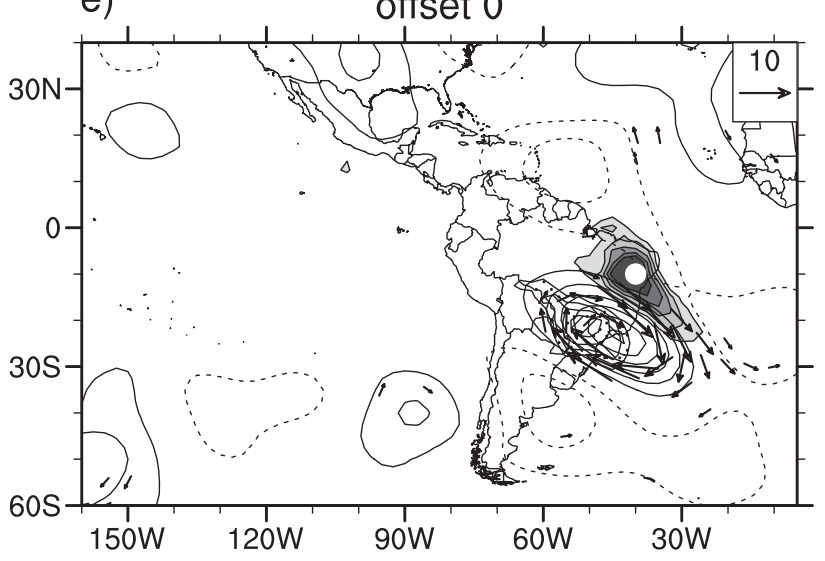

f)
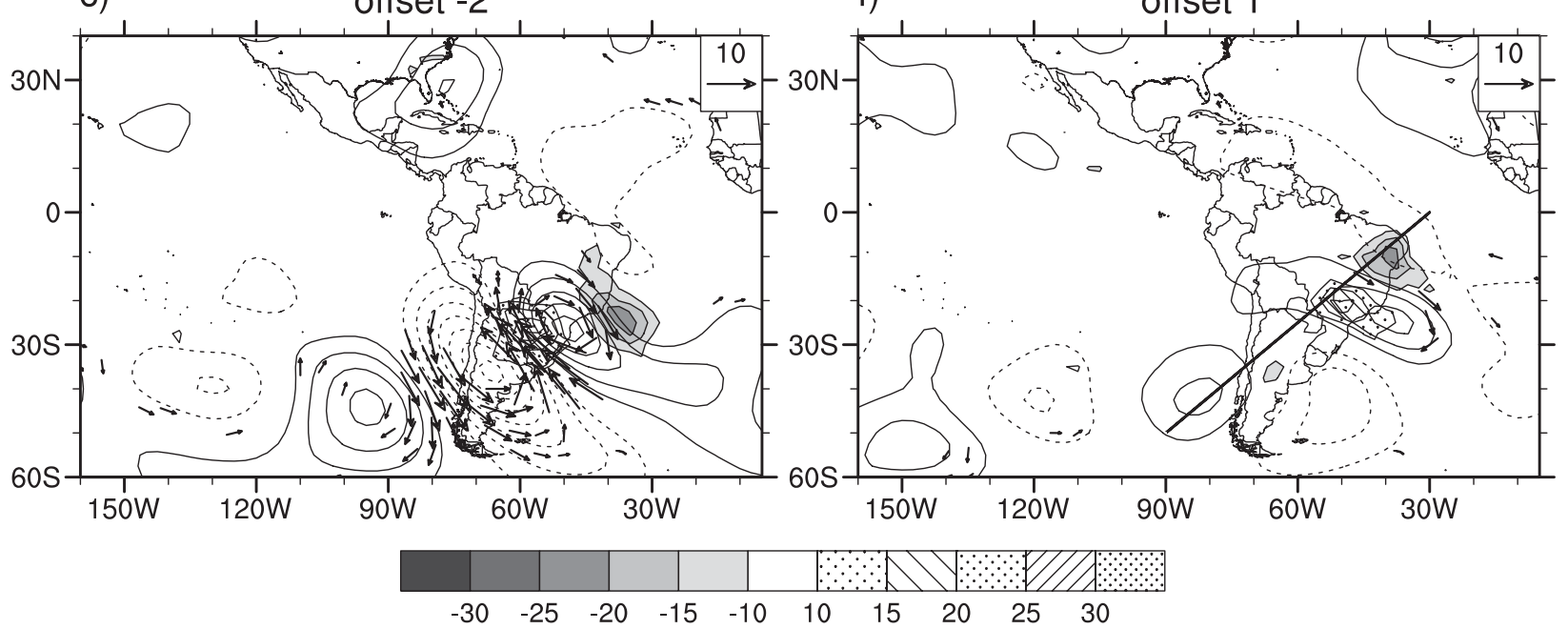

FIG. 6. Composite of 52 independent dates on which precipitation at the interior grid point (marked by a white dot on the day-0 map) was at least 2 standard deviations above the annual mean, subject to the additional constraint that 200-mb southeasterly wind anomalies at $27.5^{\circ} \mathrm{S}, 55^{\circ} \mathrm{W}$ (marked by the white dot on the day- 1 map) were 1 standard deviation above their annual mean 1 day prior to the precipitation event. Contours are of 30-day high-pass filtered 200 -mb streamfunction anomalies with an interval of $1.5 \times 10^{6} \mathrm{~m}^{2} \mathrm{~s}^{-2}$, with the 0 contour omitted and negative contours dashed. Shading represents 30-day high-pass filtered OLR anomalies $\left(\mathrm{W} \mathrm{m}^{-2}\right)$, and arrows represent 30-day high-pass filtered wind anomalies $\left(\mathrm{m} \mathrm{s}^{-1}\right)$ at $200 \mathrm{mb}$. The diagonal line in Fig. $6 \mathrm{f}$ is used in computation of Figs. 7 and 9. 
documented in those studies and also in studies of cold air outbreaks by Garreaud and Wallace (1998) for summer and Vera and Vigliarolo (2000) for winter. These other disturbances also propagate more zonally than those shown here, which have their major axes more tilted in a northwest-southeast direction and therefore are more able to reach the deep tropics.

The statistical significance of the pattern shown in Fig. 6 is estimated by a Monte Carlo approach (similar to the technique to assess local significance of the wind vectors) that compares the number of events (all dates) at the base point with a qualifying precursor to an estimation of how many of these events would be expected by chance. The number of chance occurrences is estimated by determining the correspondence for each combination of mismatched years (e.g., the 1979 precipitation dates are compared with the precursor wind dates for years 1980 to 2005 successively, etc.). There is an average of 37 "random" events per 27 mismatched years. All matches are counted. Since there were 52 nonconsecutive precipitation and wind dates that actually "coincided" (with a 1-day difference), and because the spatial pattern is realistic, the composite is deemed significant.

The vertical structure of the disturbances that originate in the Southern Hemisphere and are associated with precipitation at the interior grid point is now examined by means of pressure-latitude cross sections. The abscissa is latitude along the southwest-northeastoriented line shown in Fig. 6f. Figure 7 shows the filtered streamfunction anomalies in the vertical for each offset corresponding to Fig. 6 . At $50^{\circ} \mathrm{S}$ the disturbance structure is equivalent barotropic, with maximum amplitude close to $300 \mathrm{mb}$. This is the typical vertical structure of synoptic disturbances observed over the open ocean in both the Southern (e.g., Kidson 1991) and Northern (Hsu 1987) Hemispheres. As the composite disturbance progresses toward the equator, the level of the maximum anomaly increases, while the anomaly at the surface tends to weaken (e.g., Fig. 7d; day -1). Similar behavior is also seen in the geopotential height field (not shown).

This differential amplitude in the vertical structure is similar to that observed for disturbances propagating equatorward in the North Pacific (e.g., Tomas and Webster 1994; Kiladis 1998) and has been attributed to the vertical shear arising from upper-level westerlies in the upper troposphere to tropical easterlies in the lower and middle troposphere. In the present case, as the disturbance propagates northward, it encounters a dome of mean easterly winds in the longitude band from $55^{\circ}$ to $30^{\circ} \mathrm{W}$ that extends from near the surface at $30^{\circ} \mathrm{S}$ and $30^{\circ} \mathrm{N}$ to about $300 \mathrm{mb}$ at the equator (Fig. 8). Since the disturbance is nearly stationary and since, according to linear wave theory, a stationary Rossby wave cannot propagate through a critical layer from a westerly into an easterly wind region (e.g., Hoskins and Karoly 1981), this low-level "easterly dome" would explain why the circulation anomalies weaken at low levels as they move northward (Tomas and Webster 1994). Also of relevance is the fact that, as upper tropospheric potential vorticity (PV) anomalies propagate equatorward, their depth of influence (or vertical scale) should decrease according to the Prandtl-Rossby-Burger relationship, owing to a decrease in the Coriolis parameter (Hoskins et al. 1985). Consistent with both of these arguments, the low-level signal in the anomalous streamfunction field becomes weak in the vicinity of the convection.

Temperature anomalies for the same cross section as in Fig. 7, except for offsets -2 to 0, are shown in Figs. 9a-c. In midlatitudes they are consistent with the circulation anomalies, with opposite-signed temperature perturbations located above and below the maxima in streamfunction (or height). The temperature signal weakens as the disturbance approaches the equator, although a baroclinic structure with a poleward and westward tilt persists well into the subtropics. Negative surface temperature anomalies, although weak, extend into the region of convection at $10^{\circ} \mathrm{S}$ on day 0 , consistent with Kousky (1979)'s contention that precipitation in Northeast Brazil is often associated with the remains of cold fronts.

Anomalies in the specific humidity field, on the other hand, do not diminish as the disturbance progresses northward (Figs. 9d-f). Humidity peaks within the region of convection at $10^{\circ} \mathrm{S}$, with anomalously dry conditions seen to the southwest, also characteristic of a frontal boundary. Overall, the vertical structure differs from that usually observed in a convectively coupled equatorial waves. In the majority of such disturbances, the peak moisture perturbations tend to occur at around $500 \mathrm{hPa}$ and near the top of the boundary layer (Kiladis et al. 2009), whereas these signals are largest at the surface and $700 \mathrm{hPa}$ in Figs. 9d-f. This may reflect a relative lack of deep convective activity as opposed to more shallow rain processes, as might be expected in a weak frontal environment.

A second pattern associated with precipitation at the interior grid point, similar in structure to the one just described (Fig. 6) but originating in the Northern Hemisphere (Fig. 10), is obtained by requiring, as an additional constraint, a northeasterly $200-\mathrm{mb}$ wind of at least one standard deviation above the mean on day -1 at $10^{\circ} \mathrm{N}$, $57.5^{\circ} \mathrm{W}$, again fine-tuned through experimentation. There are 66 dates that satisfy this criterion, while the desynchronization statistical estimation technique yields an expected count of 59 dates, so the pattern is deemed as marginally significant. Although there are seven dates in 

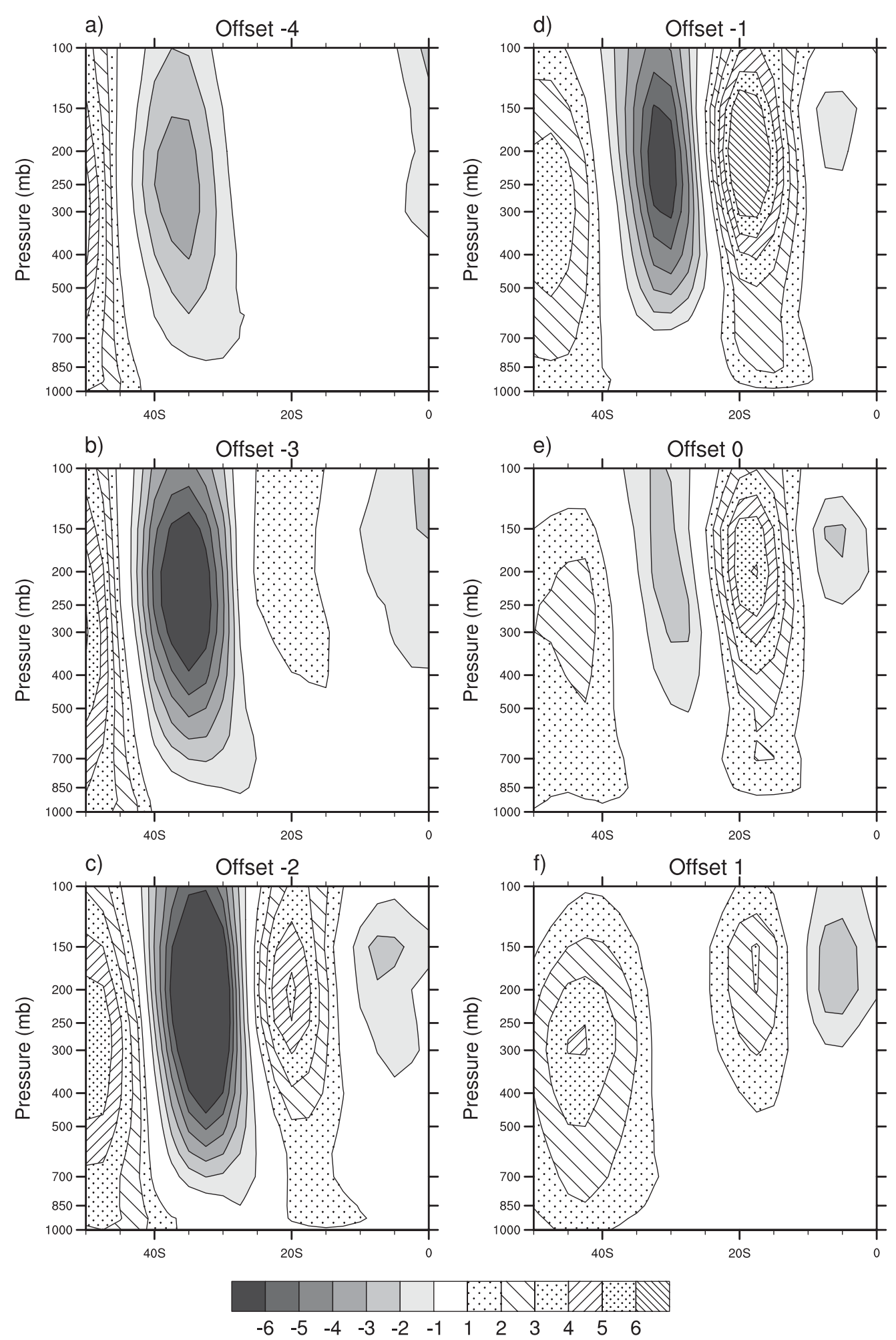

FIG. 7. Composite of 30-day high-pass filtered streamfunction anomalies for same dates used to construct Fig. 6. Anomalies are along the line shown in Fig. 6f. Shading is in $10^{6} \mathrm{~m}^{2} \mathrm{~s}^{-2}$. 


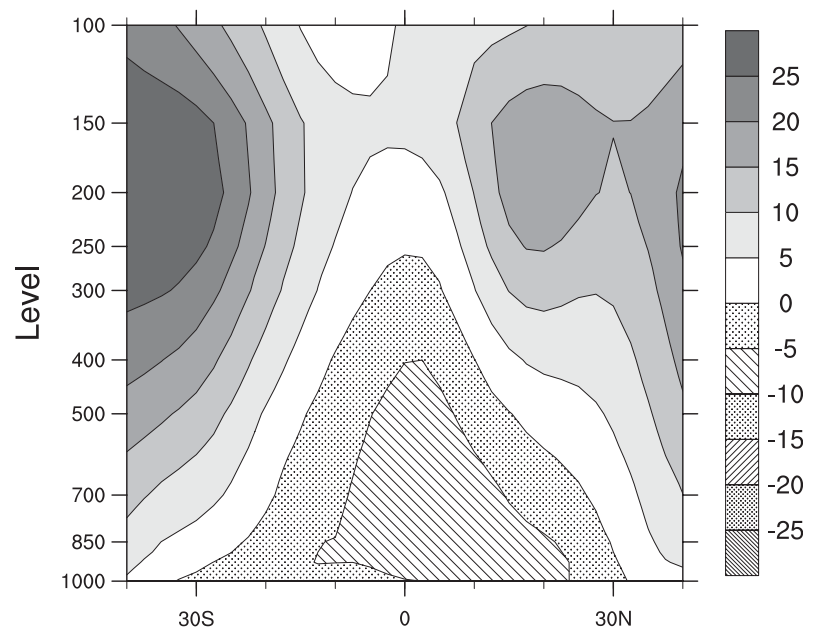

FIG. 8. Annual average zonal wind $\left(\mathrm{m} \mathrm{s}^{-1}\right)$ averaged from $55^{\circ}$ to $30^{\circ} \mathrm{W}$.

common with the 52 dates that comprise the Northern Hemisphere pattern (Fig. 6), excluding these common dates from the composites does not make a noticeable change in either pattern. In this case the convective signal again occurs southeastward of what would be classified as an upper trough in the Northern Hemisphere, even though the OLR pattern is well south of the equator. The dynamics of this type of event are therefore less clear. The authors have been unable to find any discussion of these cross-equatorial upper-level events in the literature in relation to Northeast Brazil precipitation, although Molion and Bernardo (2002) noted crossequatorial frontal penetration into northern Northeast Brazil, particularly during La Niña events. Vertical cross sections of temperature and humidity (not shown) are similar to those for the Southern Hemisphere pattern but are displaced southward, relatively symmetric about the rainfall center at $10^{\circ} \mathrm{S}$. The temperature signal, however, is not frontal in nature but instead shows a weak cold anomaly centered at $700 \mathrm{mb}$ over an even weaker warm anomaly near the surface, implying reduced static stability. While the origin of these temperature signals is unclear, it is unlikely to be related to advection, since the circulation anomalies at these levels are quite small.

At low levels, the composites for disturbances originating in the Southern and Northern Hemispheres share some common features, namely westerlies near the base point and a cyclone to its south (not shown). This commonality explains why those features are evident and significant in the otherwise washed-out composites of Fig. 5. While for the Southern Hemisphere-originating disturbances the cyclone is dynamically consistent with the upper-level wave train (Fig. 6), the connection is less clear for the Northern Hemisphere-originating disturbance (Fig. 10).

The midlatitude-originating waves discussed above are expected to vary with season. This seasonality can be examined by taking the wind events at the precursor locations as a proxy for wave activity with the potential to affect Northeast Brazil precipitation. The average monthly count of one-standard-deviation wind events used as additional criteria for the composites in Figs. 6 and 10 is shown in Fig. 11. As one would anticipate, the highest counts occur in the respective winter seasons, when midlatitude baroclinic activity is strongest. Thus, it appears that the limiting factor for precipitation at the interior grid point during the dry season (May-October) is not the absence of wave activity (since this is the peak time of occurrence of SH wave events) but more likely the northward migration of the equatorial trough and associated low-level confluence, as suggested by Hastenrath and Lamb (1977). There may also be additional seasonal changes to unfavorable conditions, such as a shift in the basic-state zonal wind that the SH wave train encounters as it propagates equatorward.

Figure 12 shows the count per month of the dates that entered the composites in Figs. 6 and 10. From December to April, which comprises most of the wet season, events originating in the Northern Hemisphere dominate, seemingly reflecting the favorable timing of this hemisphere annual cycle of baroclinic wave activity. During the rest of the year, there is an about equal number of events initiated from either hemisphere or slightly fewer NH-initiated events. Note that about half $(45 \%)$ of all the two-standard-deviation independent precipitation events (260) are included in these composite dates.

\section{b. Coastal grid point}

Large filtered precipitation anomalies at the interior grid point are, somewhat surprisingly, nearly unrelated to those at the coastal grid point, suggesting that different mechanisms are responsible for precipitation at each location. There are 345 and 314 dates with two standard deviation anomalies at the interior and coastal grid points, respectively, but only 40 common dates (and 45 common dates if the interior dates lead by one day). While this is more than the 22 dates expected to occur from random chance (based on a Monte Carlo estimate), it is much less than one would expect if the same circulation patterns contributed to precipitation variability at both points.

Figure 13 is produced by lead-lag compositing the largest anomalies in a sequence of two standard precipitation anomaly events (day 0) at the coastal grid 

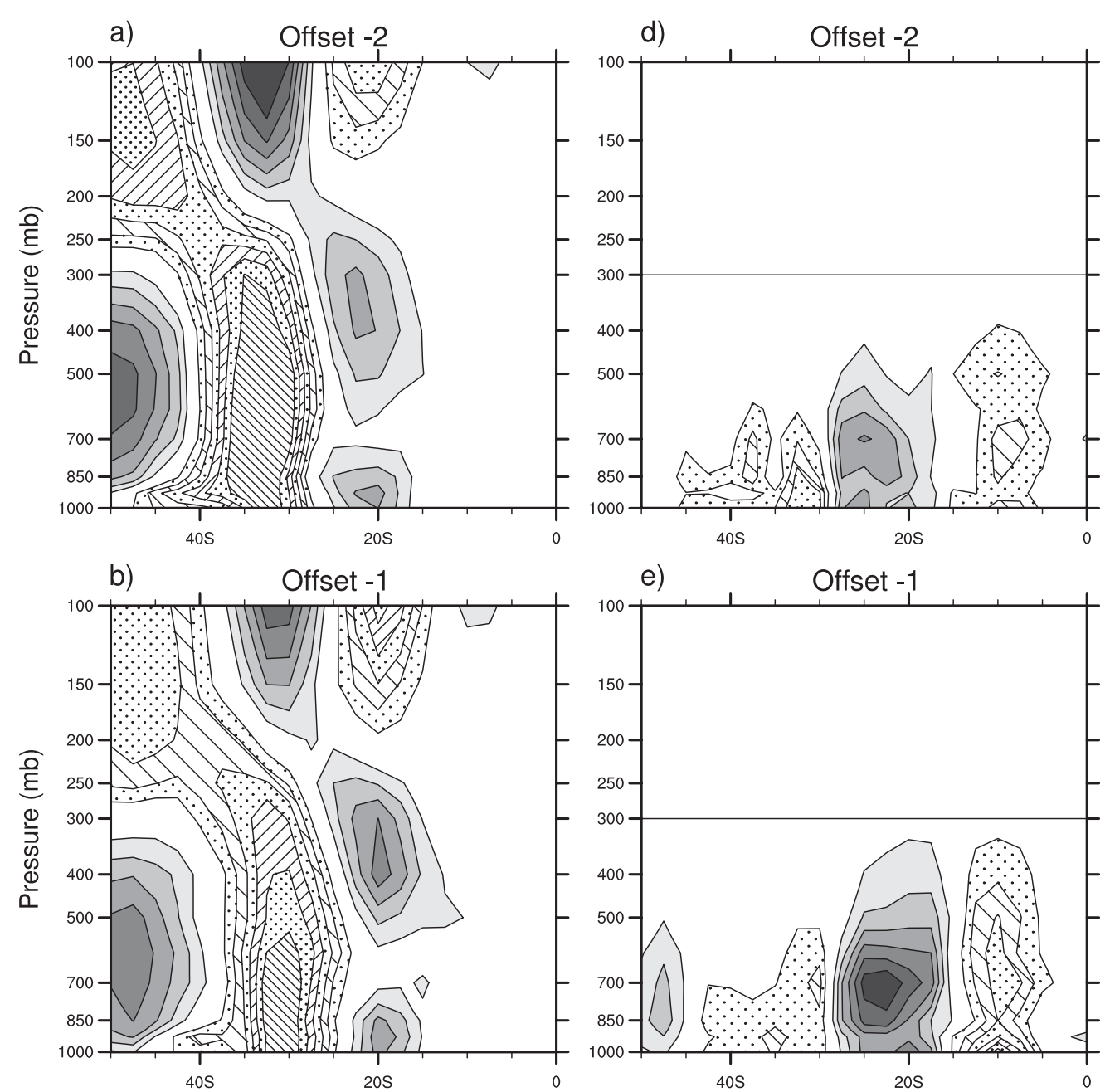

e)
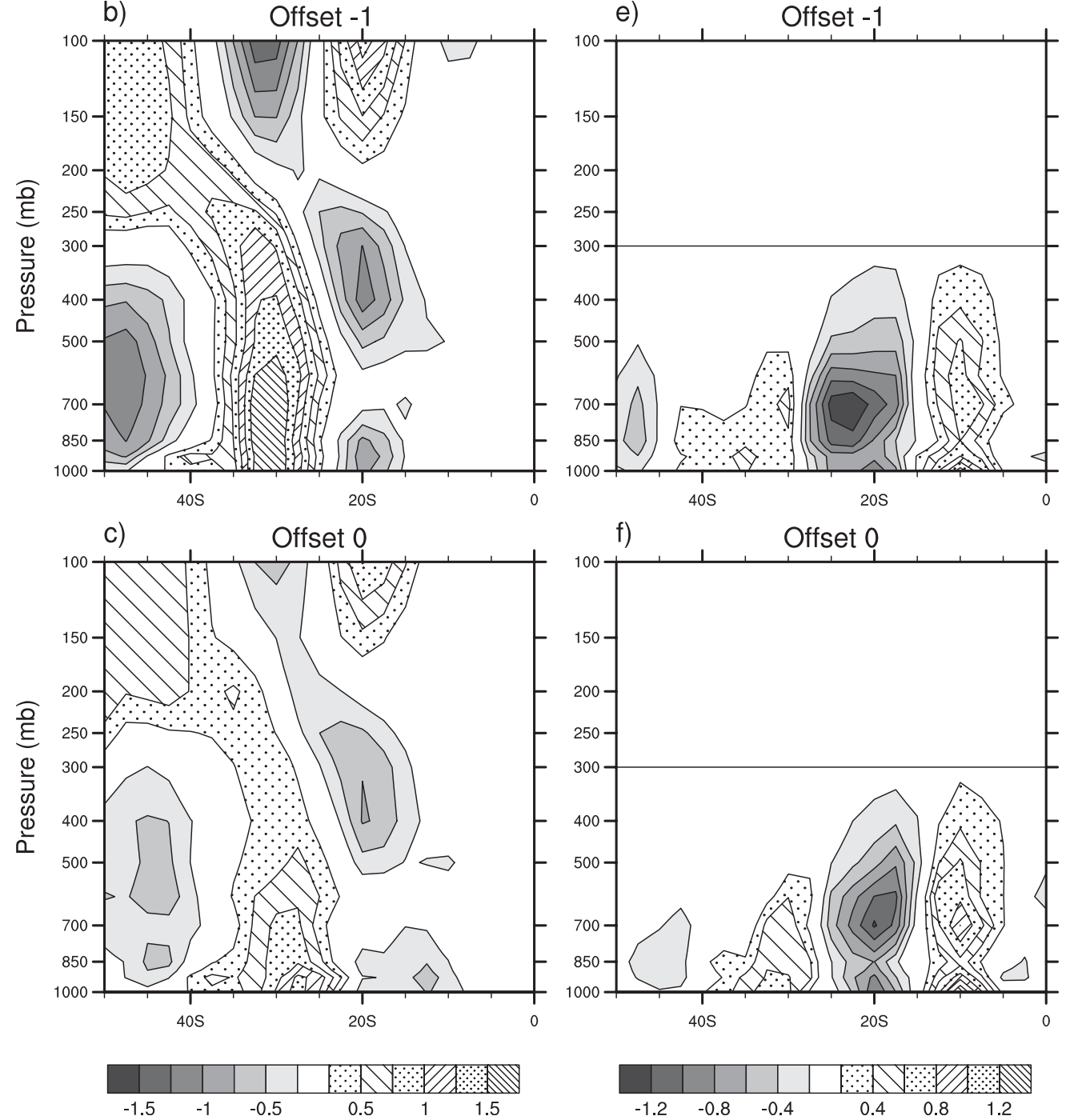

FIG. 9. As in Fig. 7, except composited quantities are (a)-(c) 30-day high-pass filtered temperature anomalies $\left({ }^{\circ} \mathrm{C}\right)$ and (d)-(f) specific humidity anomalies $\left(\mathrm{g} \mathrm{kg}^{-1}\right)$. Note that the specific humidity data are available only up to $300 \mathrm{hPa}$. 
a)

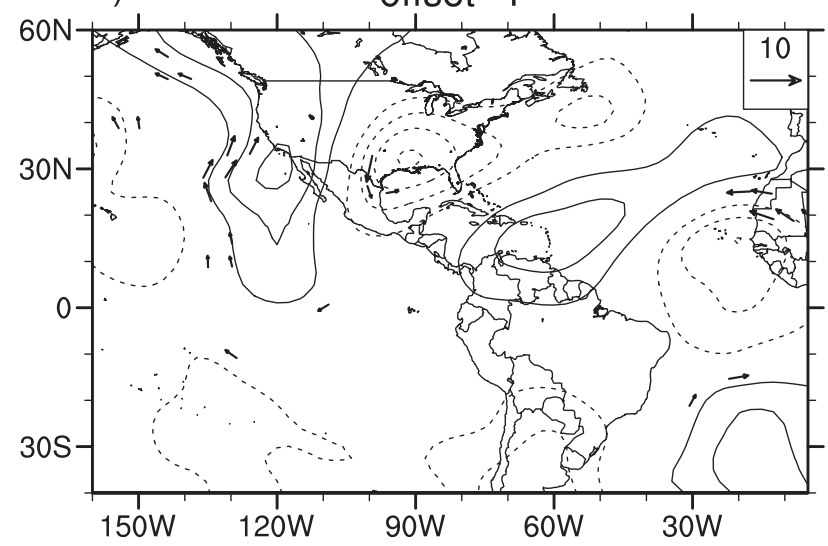

b)

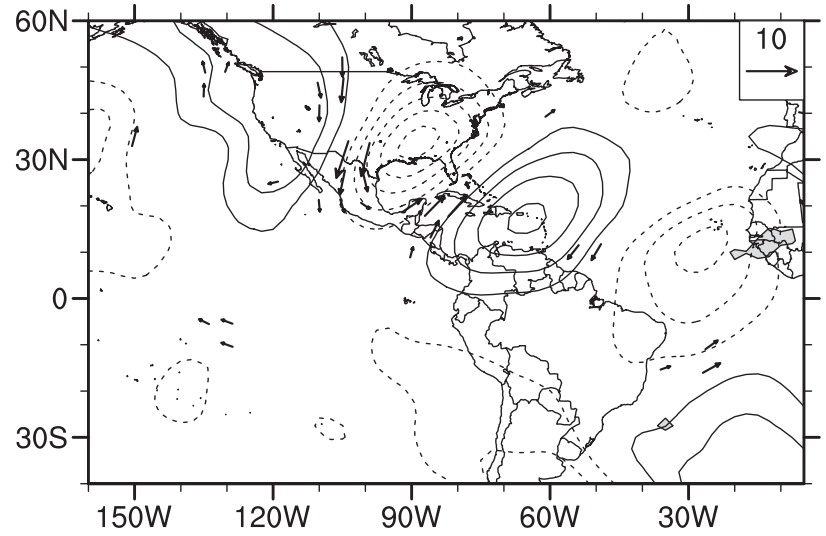

c)

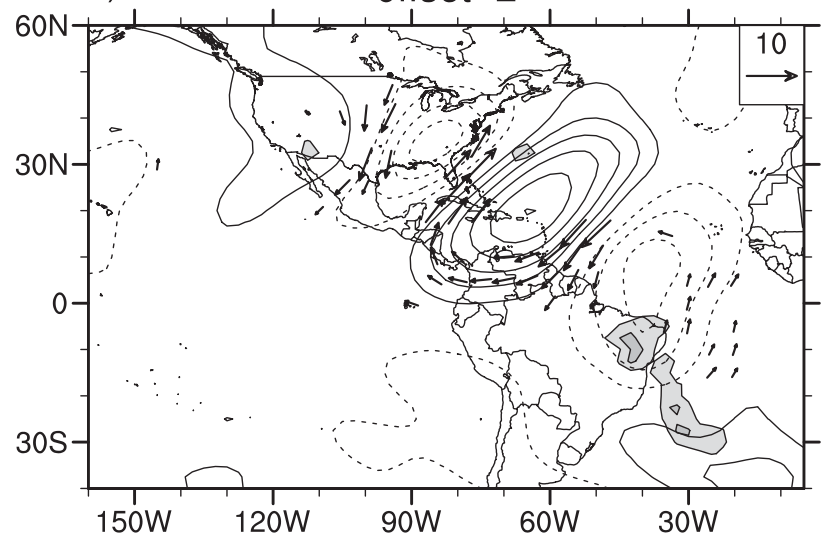

d)

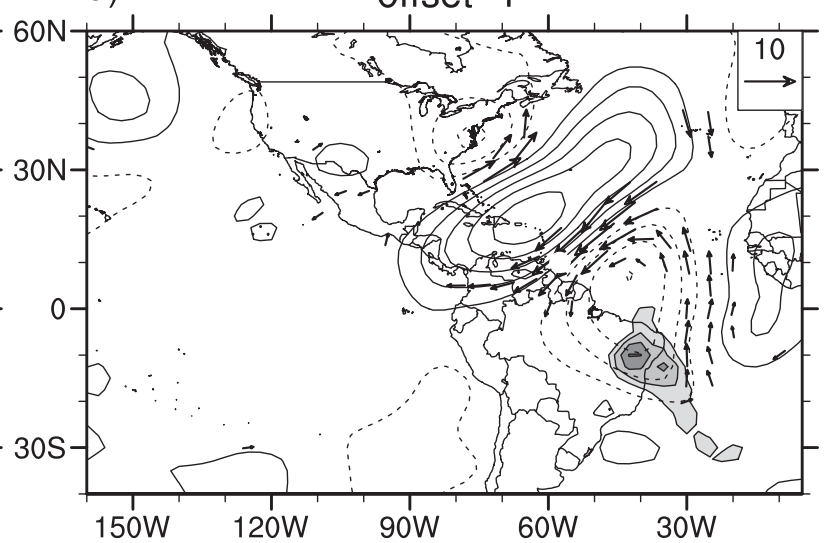

e) offset 0

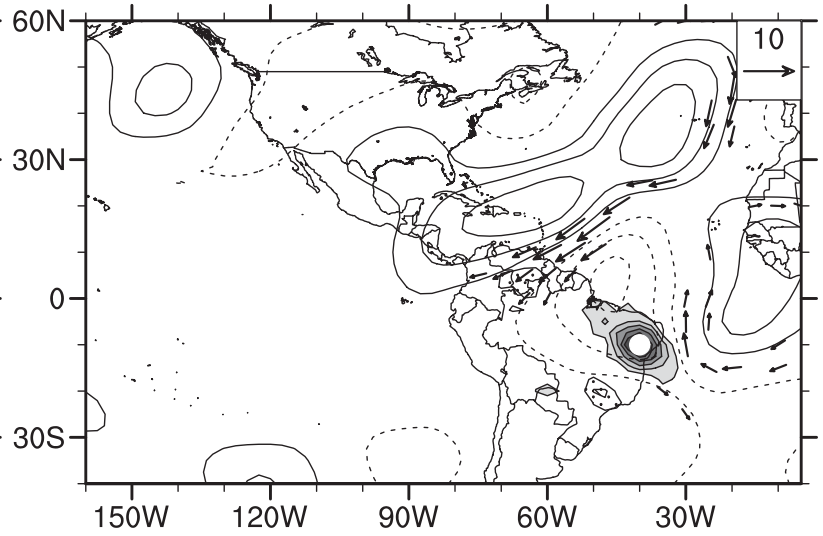

f)
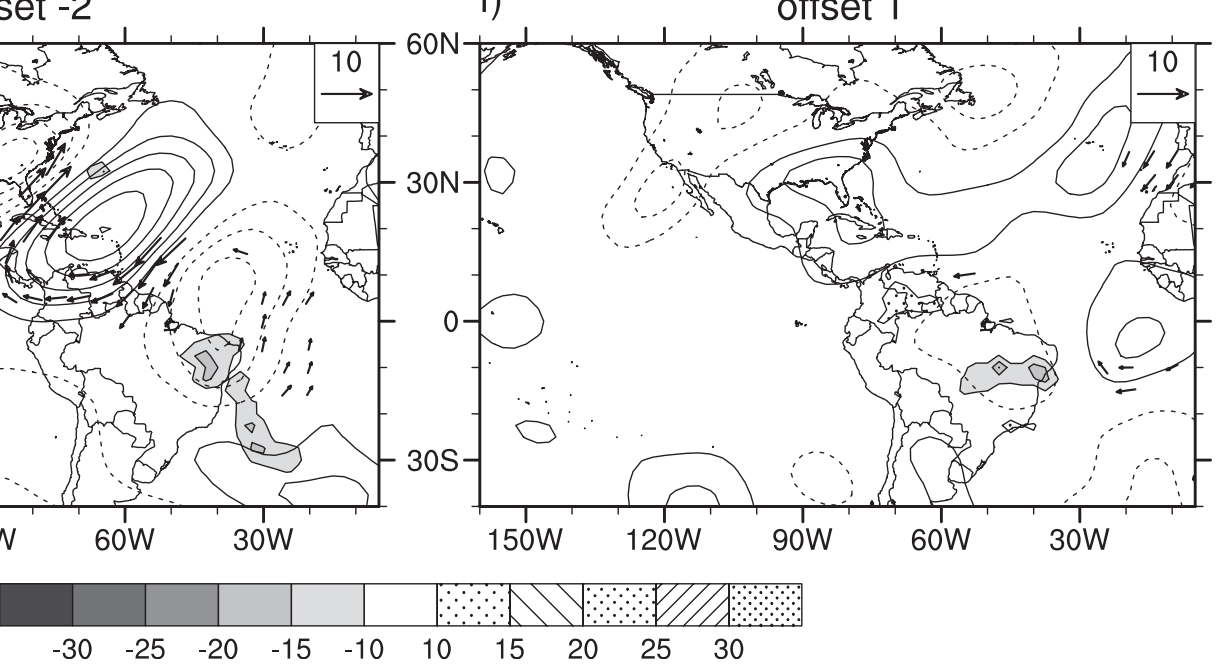

FIG. 10. Composite of 66 independent dates on which precipitation at the interior grid point was at least 2 standard deviations above the annual mean, subject to the additional constraint that 200 -mb northeasterly wind anomalies at $10^{\circ} \mathrm{N}, 57.5^{\circ} \mathrm{W}$ (marked by the white dot on the day -1 map) were 1 standard deviation above their annual mean 1 day prior to the precipitation event. Contours, shading, and vectors represent the same quantities and are at the same intervals as in Fig. 6. 


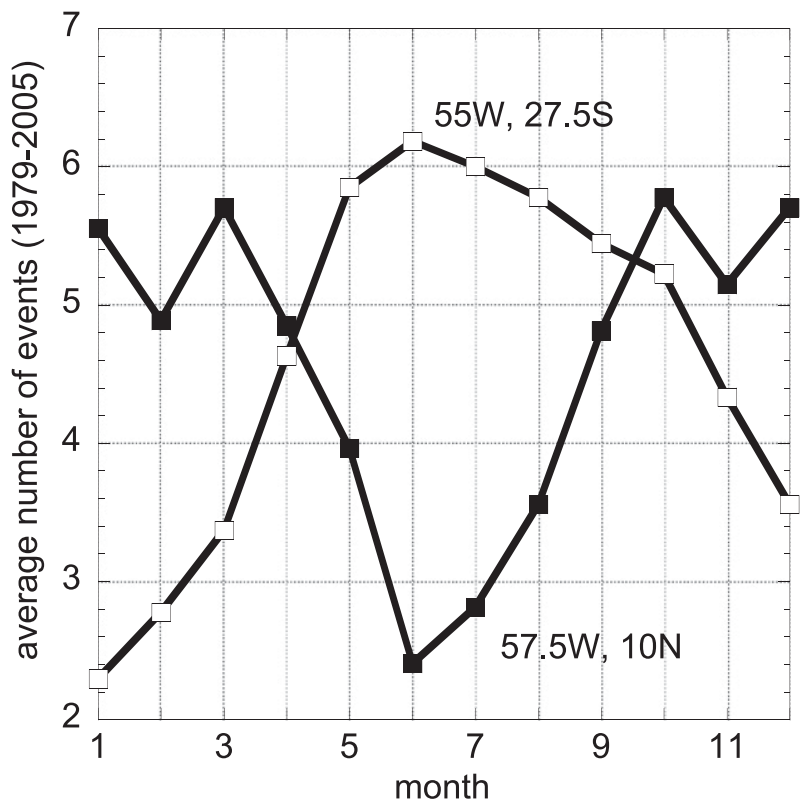

FIG. 11. Average number of occurrences per month of 1-standarddeviation $200-\mathrm{mb}$ wind events from the southeast at $27.5^{\circ} \mathrm{S}, 55^{\circ} \mathrm{W}$ (open squares) and from the northeast at $10^{\circ} \mathrm{N}, 57.5^{\circ} \mathrm{W}$ (filled squares).

point $\left(5^{\circ} \mathrm{S}, 37.5^{\circ} \mathrm{W}\right)$. It would be nearly featureless if the contour, shading intervals, and reference vector were not much smaller than those in Fig. 4, the analogous figure using the interior base point. Nonetheless, the map proves useful for identifying possible precursors for convection at this coastal location. For instance, on day -2 there are large 200-mb southeasterly wind anomalies at $30^{\circ} \mathrm{S}, 55^{\circ} \mathrm{W}$ (the map shows only the vector at that grid point that is statistically significant). The subcomposite obtained by requiring one-standard-deviation southeasterly anomalies at this point is almost identical to that obtained using the $27.5^{\circ} \mathrm{S}, 55^{\circ} \mathrm{W}$ grid point. The latter point is then used as a precursor because it is the same point used to produce Fig. 6, leading to some interesting comparisons. Figure 14 shows the resulting 62-date composite based on rainfall anomalies at the coastal grid point with a wind precursor at $27.5^{\circ} \mathrm{S}, 55^{\circ} \mathrm{W}$. Up until day -1 , the wave train is quite similar to, but slightly stronger than, the circulation pattern leading to precipitation at the interior grid point (Fig. 6). Subsequently, however, the ridge centered at about $40^{\circ} \mathrm{S}$ translates eastward as part of a zonally oriented wave train propagating along that latitude, rather than remaining nearly stationary, as was the case for the pattern in Fig. 6 . The vertical streamfunction, temperature, and specific humidity profiles (not shown) are qualitatively similar to those for the interior grid point.

In spite of the similarity between the Southern Hemisphere wave trains that give rise to precipitation at the

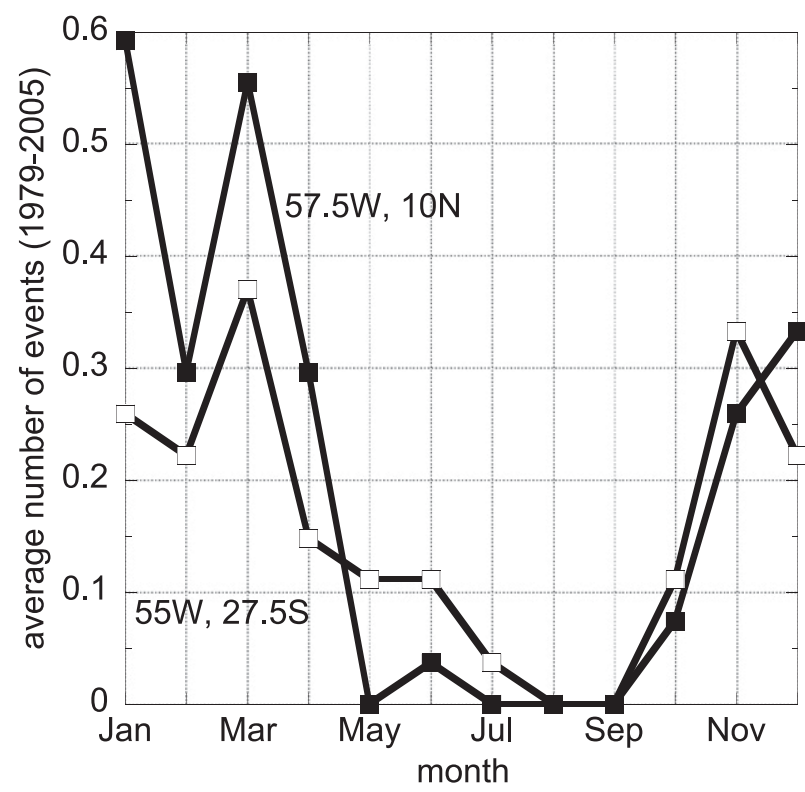

FIG. 12. Average count per month of independent 2-standarddeviation precipitation events at the interior grid point that were preceded by 1 -standard-deviation 200 -mb southeasterly wind events at $27.5^{\circ} \mathrm{S}, 55^{\circ} \mathrm{W}$ (open squares) and northeasterly winds at $10^{\circ} \mathrm{N}$, $57.5^{\circ} \mathrm{W}$ (filled squares).

coastal and interior grid points, and the fact that the same precursor is used, only 2 of the 62 (coastal) and 52 (interior) dates are in common, with the interior dates leading the coastal dates by one day. Thus, an overwhelming majority of wave train events at each point are unique; suggesting that while the impingement of extratropical wave trains into South American low latitudes is quite common, the individual disturbances leading to precipitation at fairly close locations that are nearly independent.

The same resemblance is observed between the Northern Hemisphere wave trains identified as inducing precipitation at the coast (Fig. 15) and in the interior (Fig. 10). For both figures the precursor used is one-standarddeviation northeasterly $200-\mathrm{mb}$ wind anomalies at $10^{\circ} \mathrm{N}$, $57.5^{\circ} \mathrm{W}$, with a 1-day lead. Yet again, in spite of the apparent similarities, particularly at lag 0 , only 11 of the 66 (interior) and 67 (coastal) dates are in common.

Returning to Fig. 13, weak OLR anomalies can be seen east and west of the coastal base point on day -2 . Analogous precursor OLR anomalies do not appear in the composite for the interior grid point (Fig. 4), even when the shading intervals are reduced to those of the present figure. Since it is desirable to examine the evolution of both anomalies in a consistent manner, OLR is used as a precursor. Figure 16 shows a composite for interior precipitation anomalies that are preceded at day -2 by one-standard-deviation OLR anomalies at $2.5^{\circ} \mathrm{S}, 57.5^{\circ} \mathrm{W}$. Note the smaller streamfunction contour 
a)

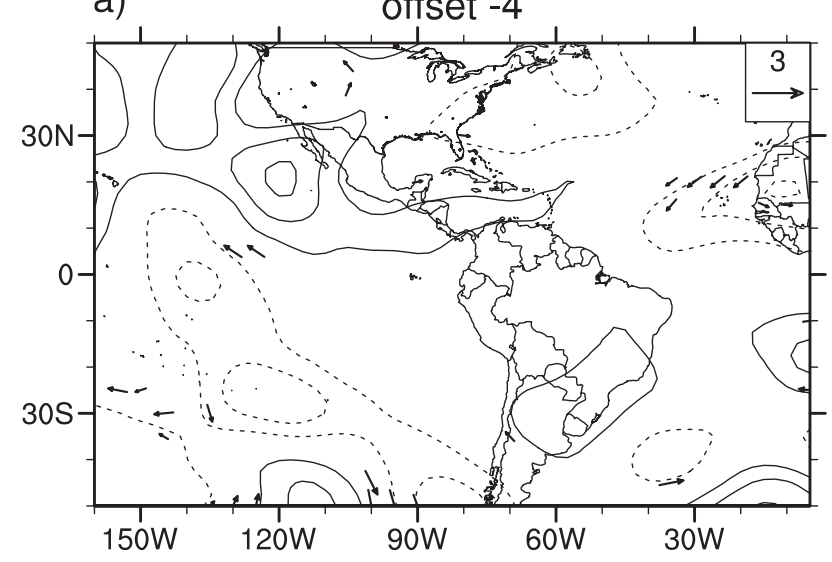

b)

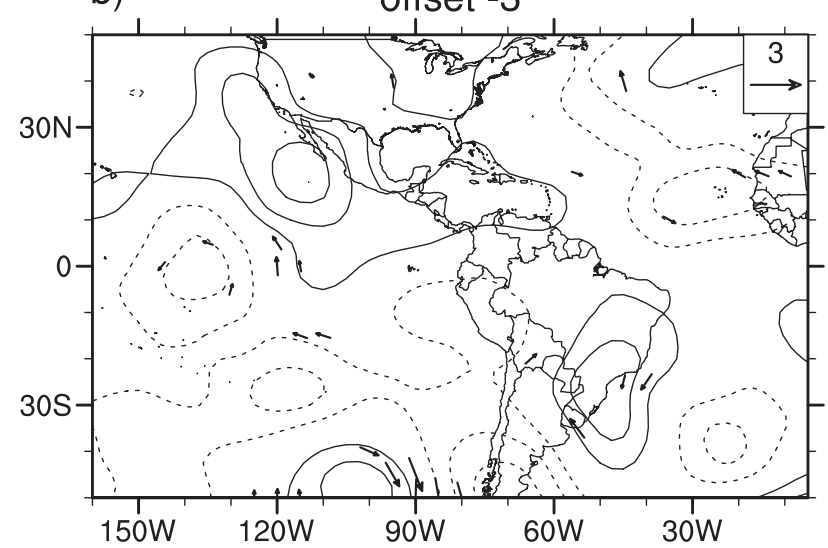

c)

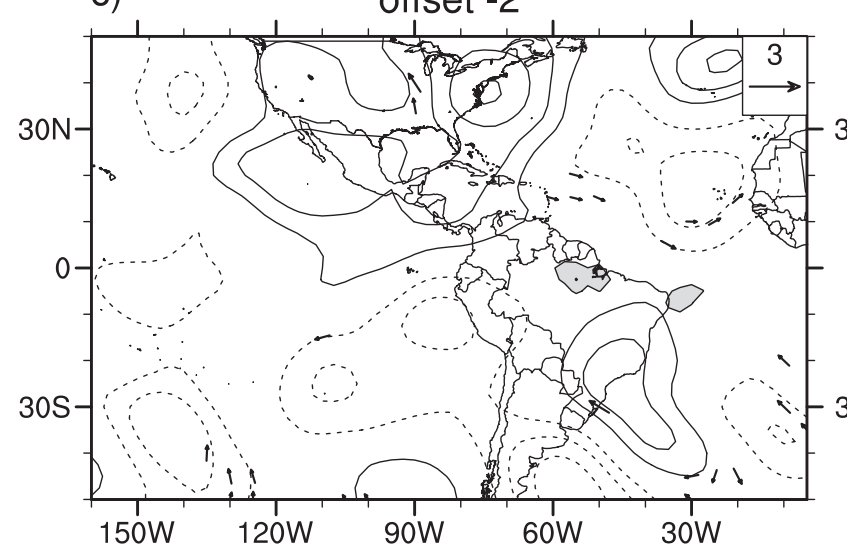

d)

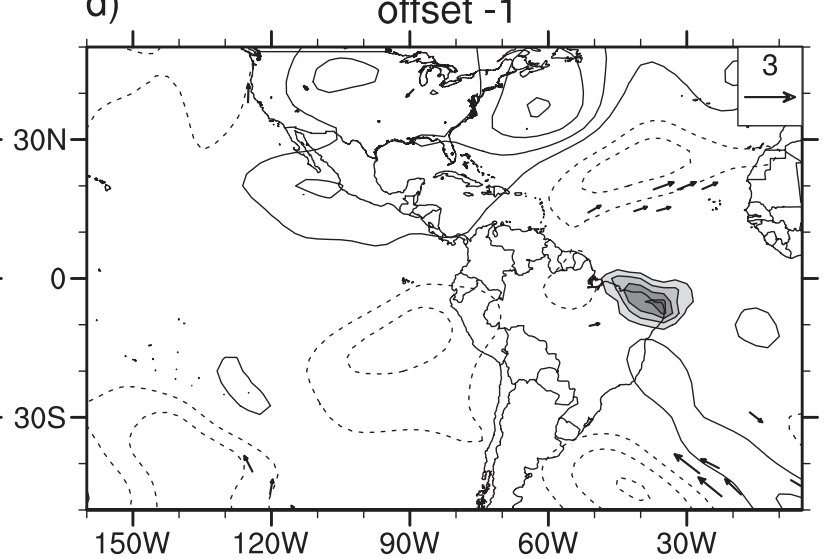

e) offset 0

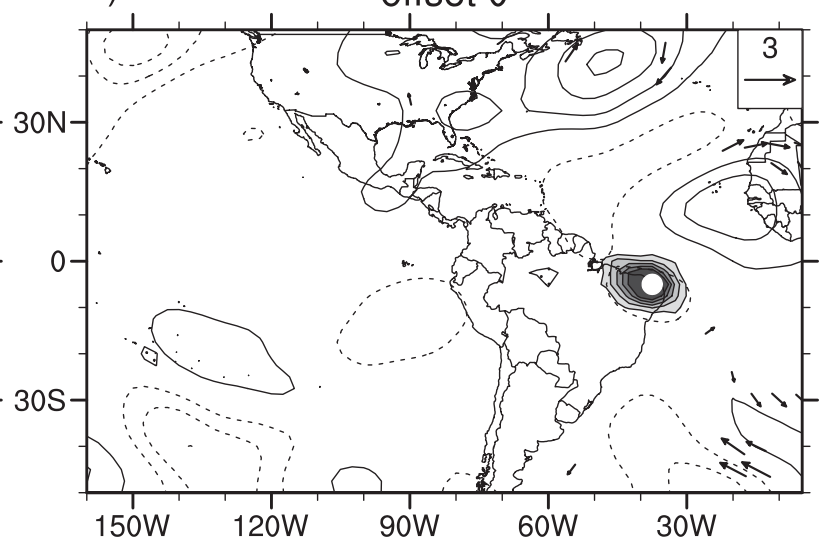

f)

offset 1
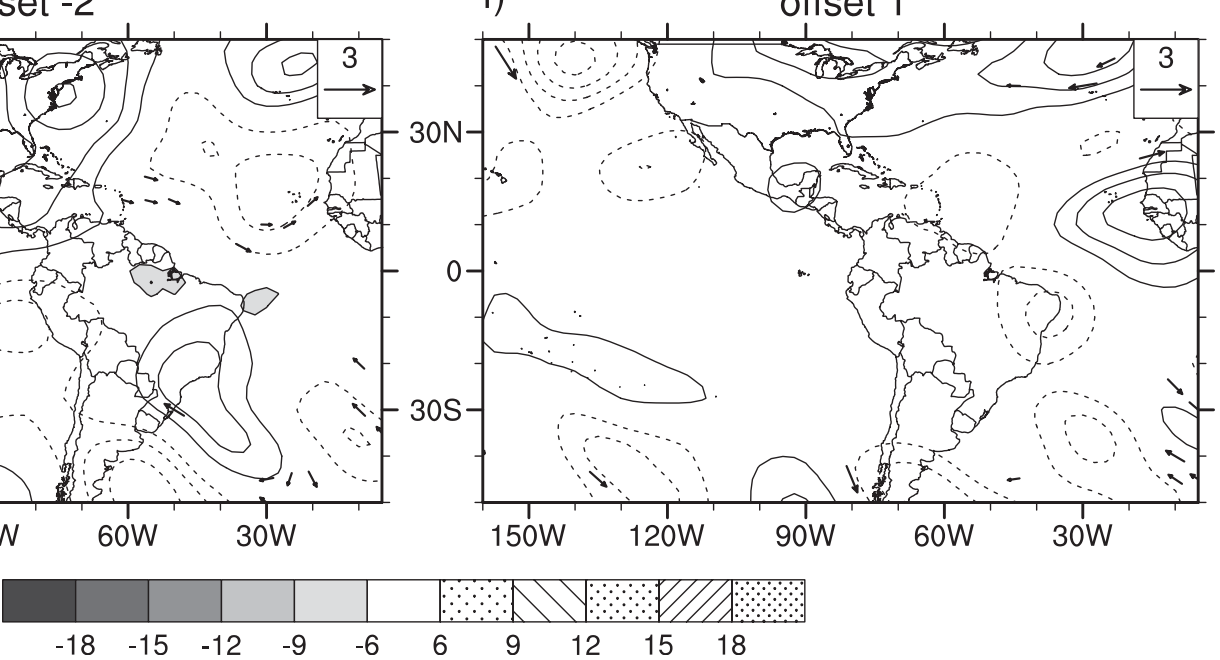

FIG. 13. Composite of 314 independent dates on which precipitation at the coastal grid point (marked by a white dot on the day 0 map) was at least 2 standard deviations above the annual mean. Only the largest value within a multiday sequence above threshold is included. Contours, shading, and vectors are as in Fig. 4. Contours are of 30-day high-pass filtered 200-mb streamfunction anomalies with an interval of $5 \times 10^{5} \mathrm{~m}^{2} \mathrm{~s}^{-2}$, with the 0 contour omitted and negative contours dashed. 
a)

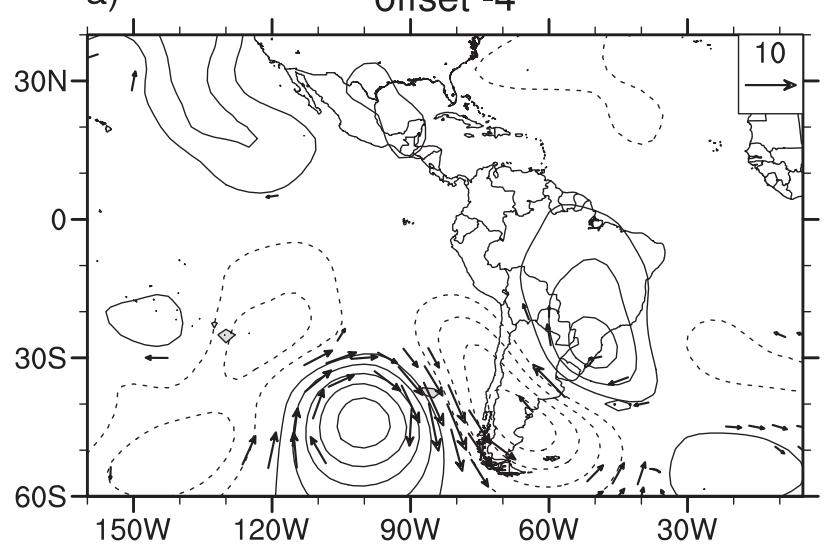

b)

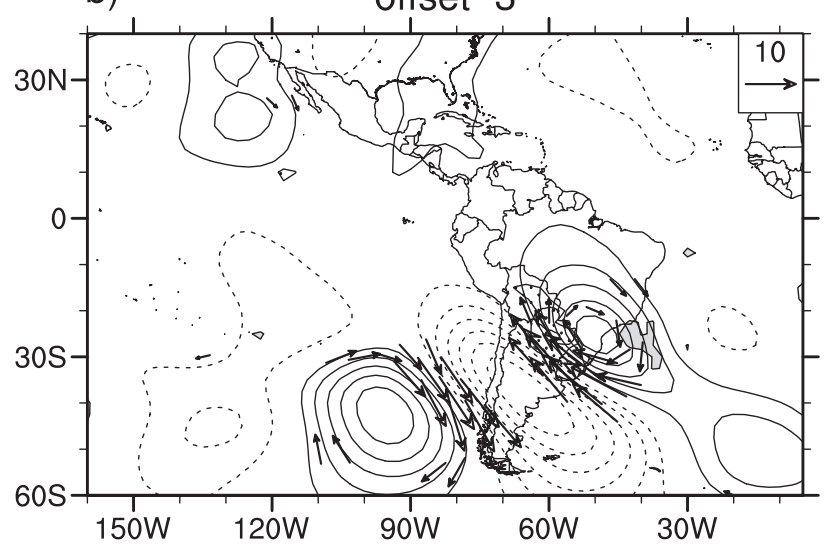

c)
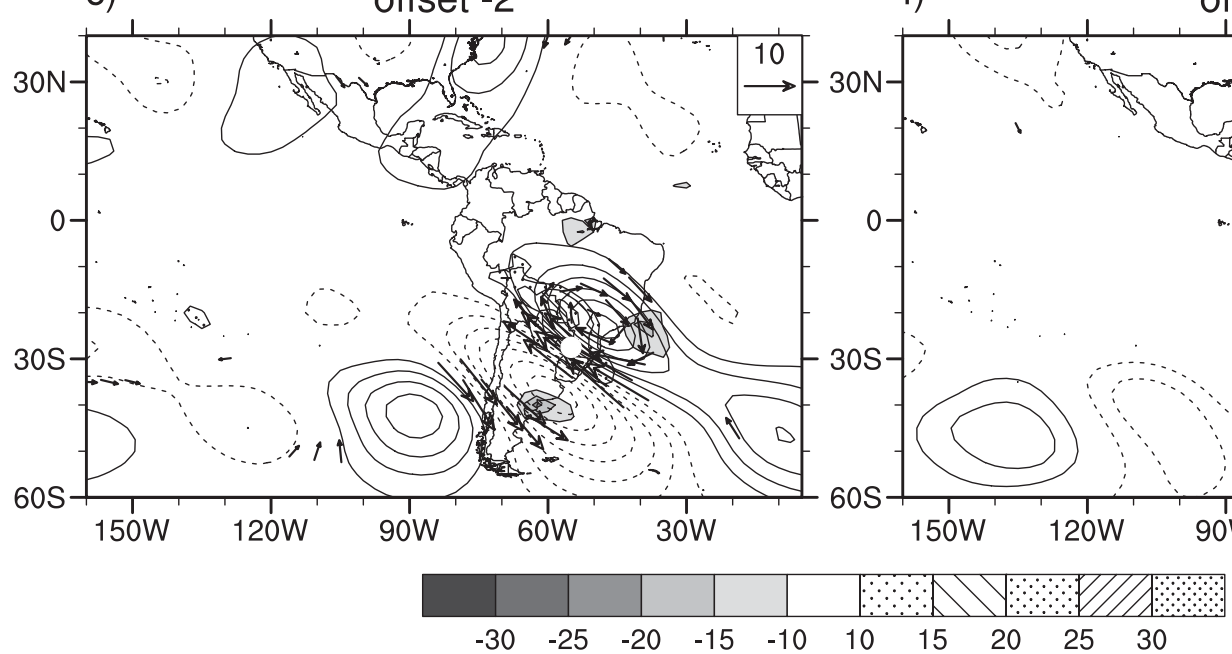

d)

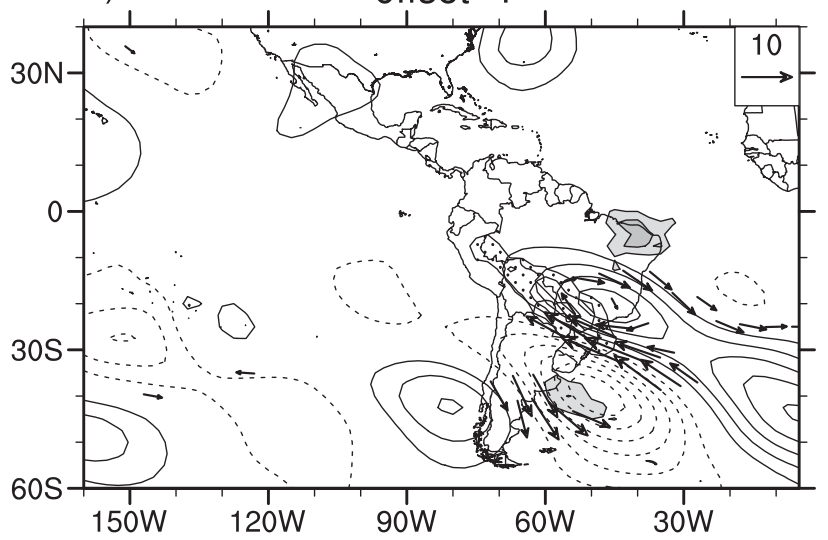

e)

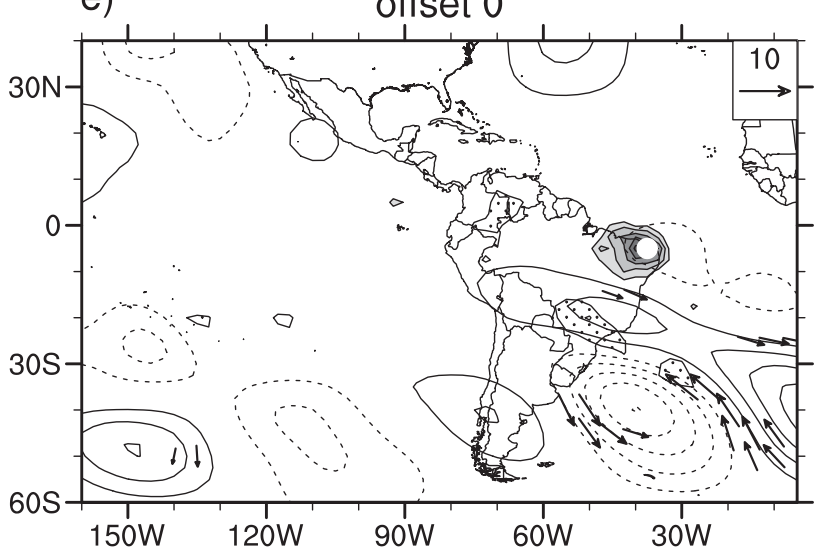

f)

offset 1

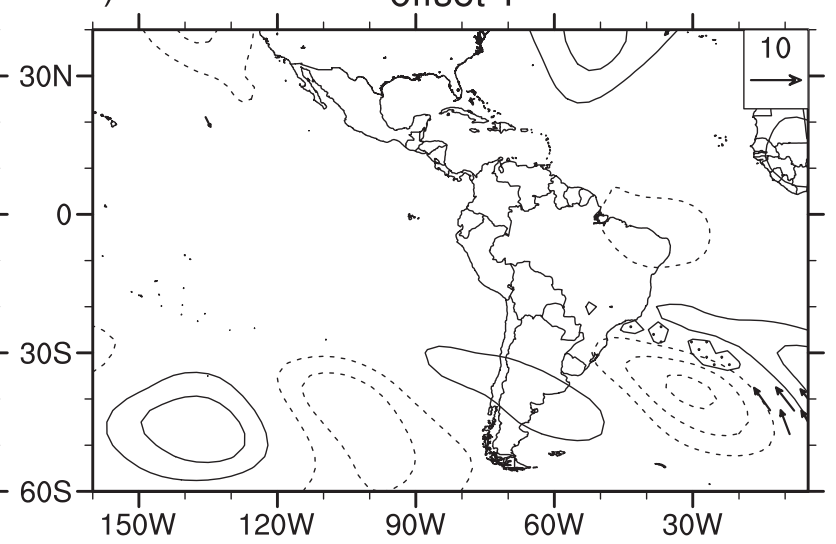

FIG. 14. Composite of 62 independent dates on which precipitation at the coastal grid point was at least 2 standard deviations above the annual mean, subject to the additional constraint that $200-\mathrm{mb}$ southeasterly wind anomalies at $27.5^{\circ} \mathrm{S}, 55^{\circ} \mathrm{W}$ (marked by the dot on the day -2 map) were 1 standard deviation above their annual mean 2 days prior to the precipitation event. Contours, shading, and vectors are as in Fig. 6. 
a)

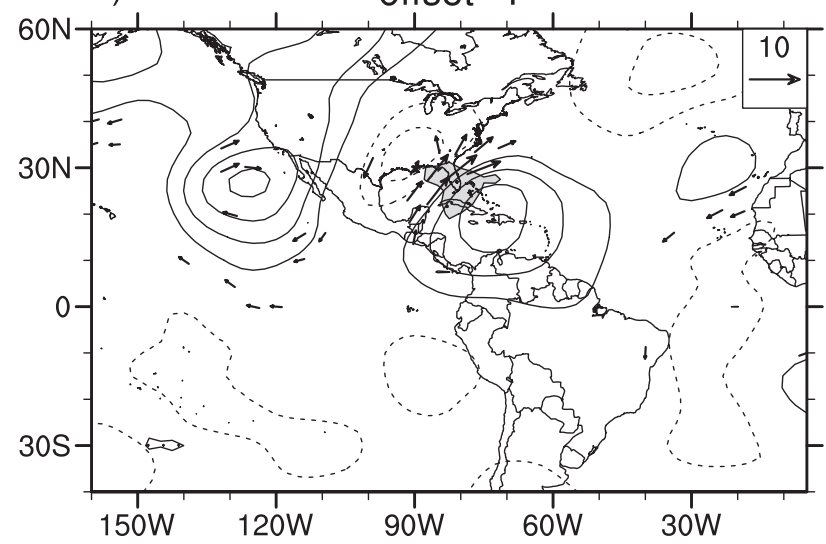

b)

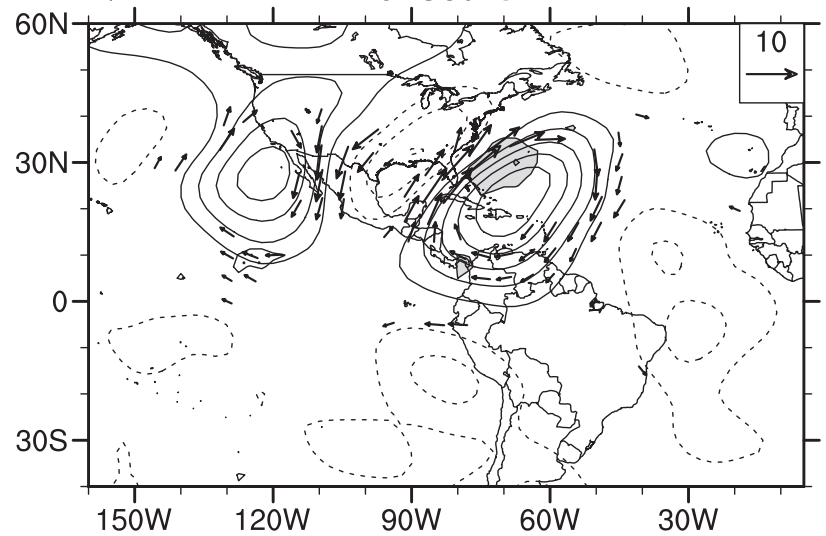

c)

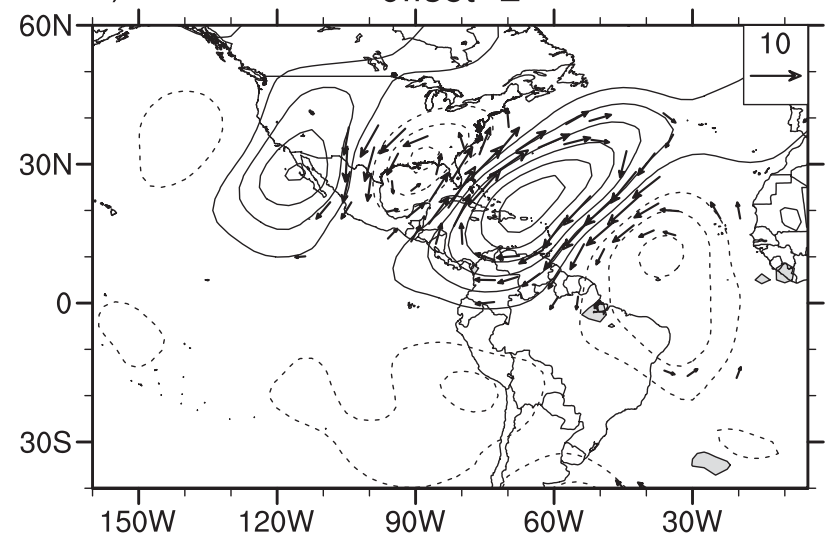

d)

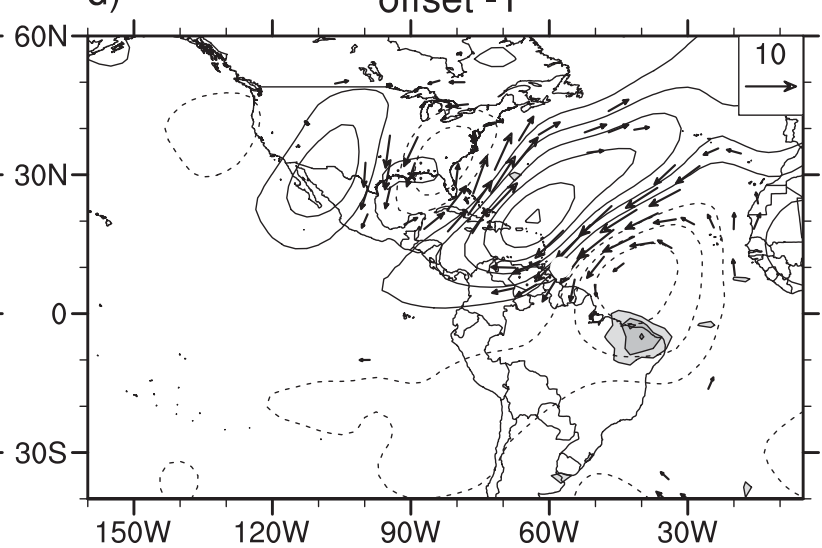

e)

offset 0

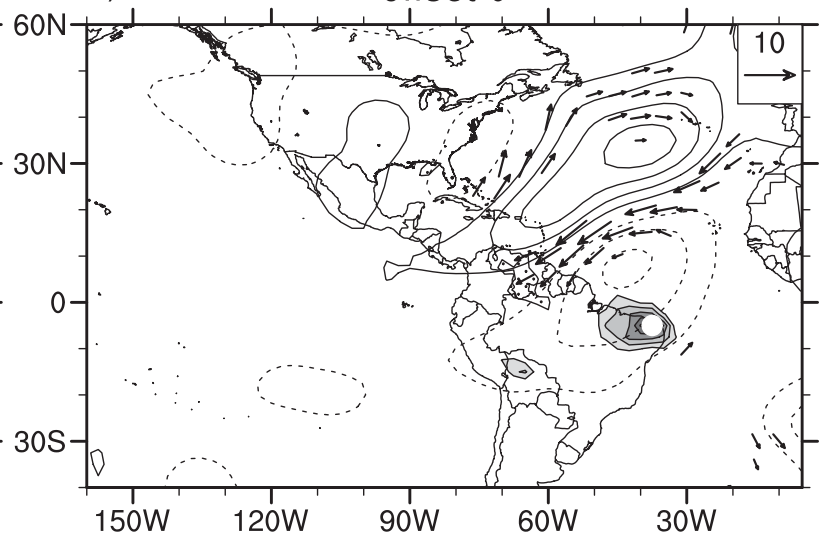

f)

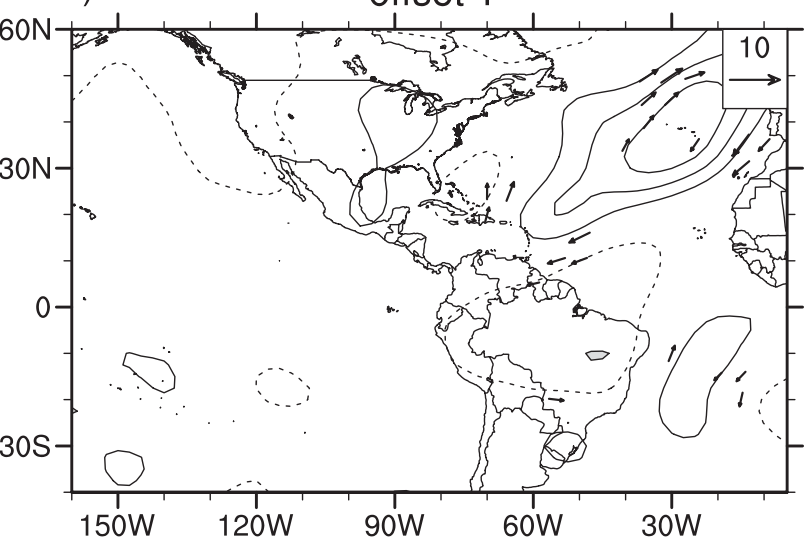

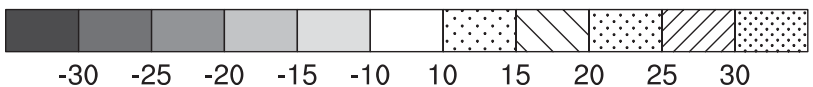

FIG. 15. Composite of 67 independent dates on which precipitation at the coastal grid point was at least 2 standard deviations above the annual mean, subject to the additional constraint that 200 -mb northeasterly wind anomalies at $10^{\circ} \mathrm{N}, 57.5^{\circ} \mathrm{W}$ (marked by the dot on the day -1 map) were 1 standard deviation above their annual mean 1 day prior to the precipitation event. Contours, shading, and vectors are as in Fig. 6. 
a)

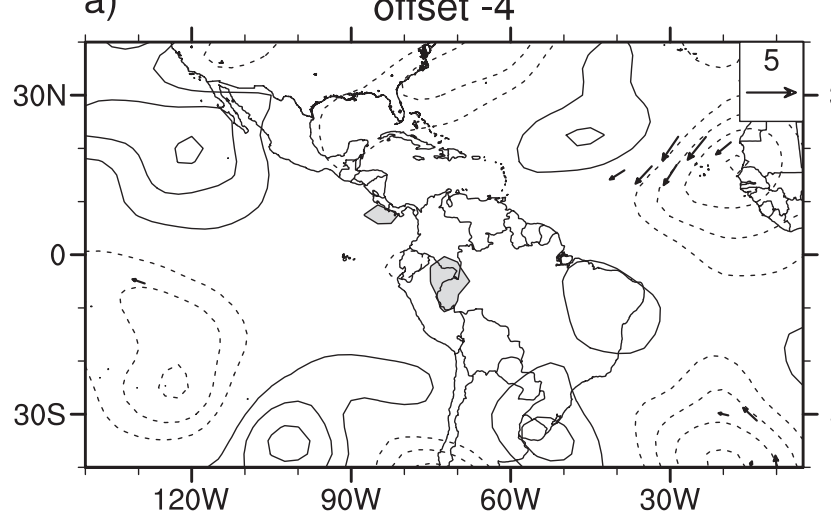

b)

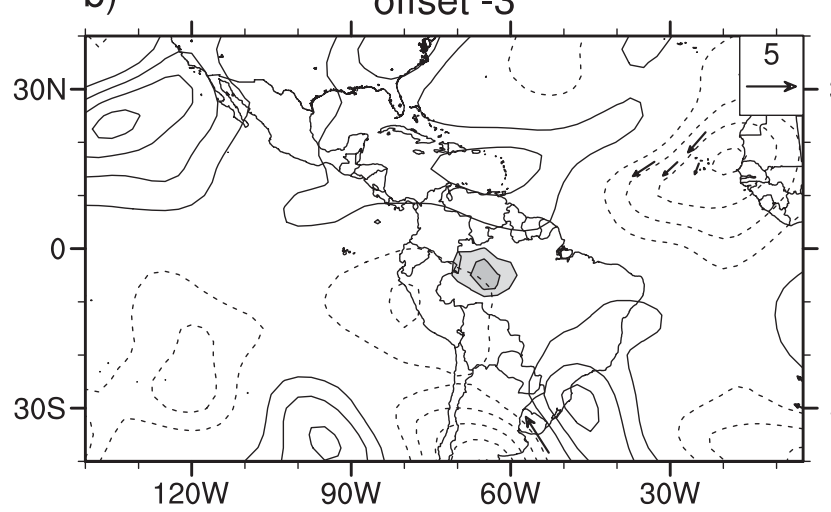

c)

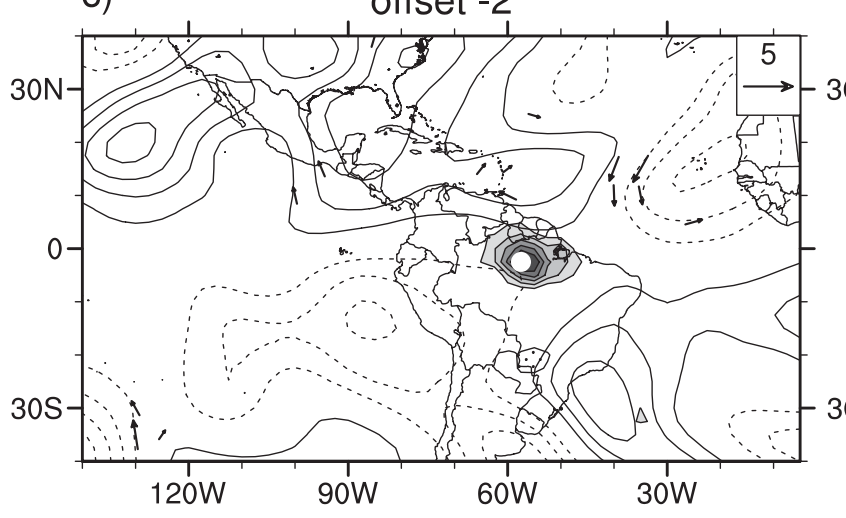

d)

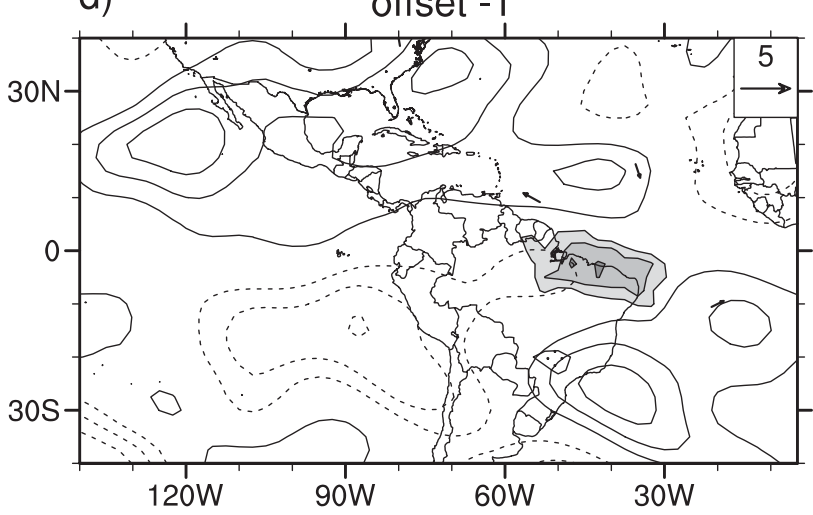

e)

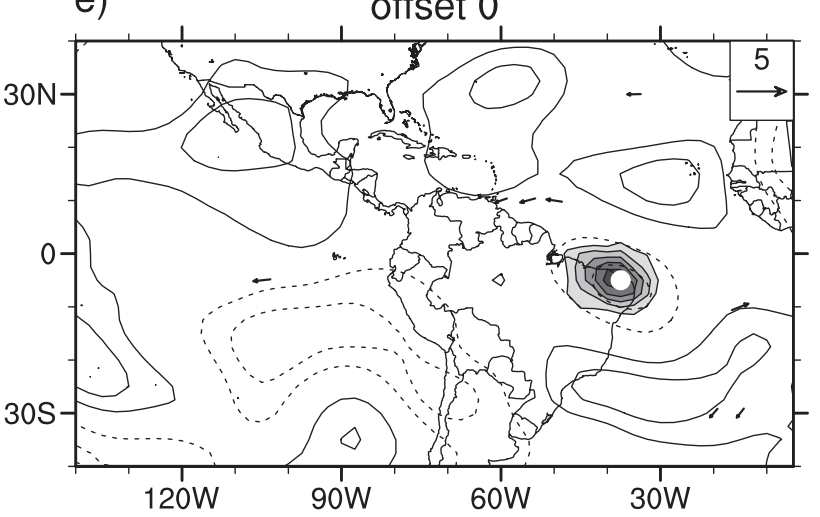

f) offset 1
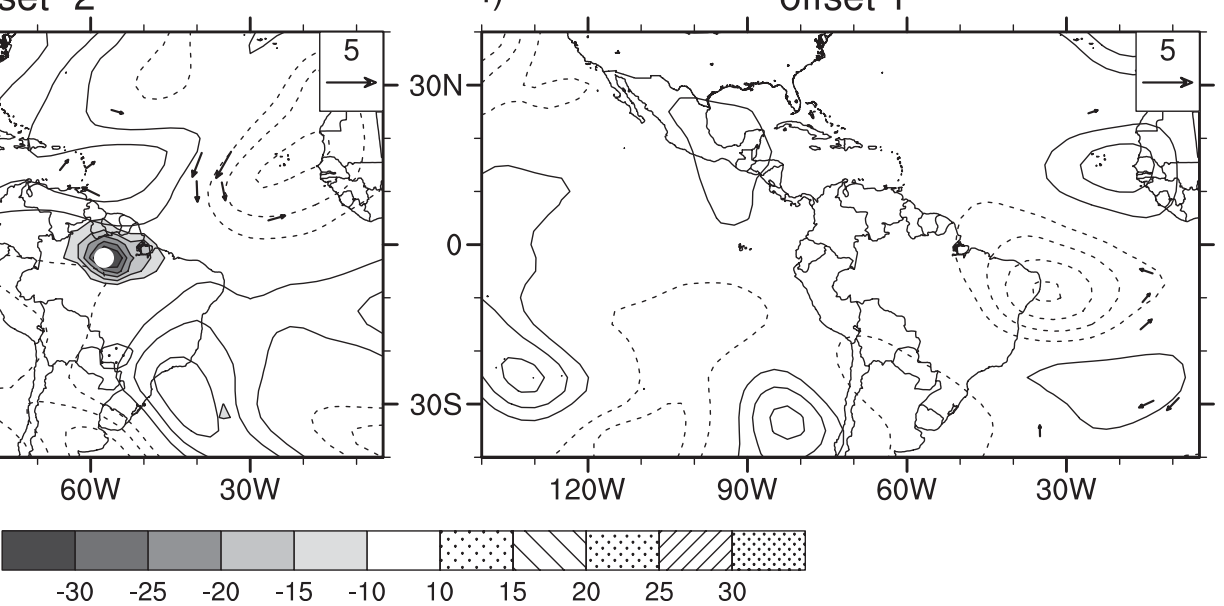

FIG. 16. Composite of 80 independent dates on which precipitation at the coastal grid point was at least 2 standard deviations above the annual mean, subject to the additional constraint that OLR anomalies at $2.5^{\circ} \mathrm{N}, 57.5^{\circ} \mathrm{W}$ (marked by the dot on the day -2 map) were $1 \mathrm{standard}$ deviation above their annual mean 2 days prior to the precipitation event. Contours, shading, and vectors are as in Fig. 6. The 200-mb streamfunction anomalies are contoured at an interval of $7.5 \times 10^{5} \mathrm{~m}^{2} \mathrm{~s}^{-2}$, with the 0 contour omitted and negative contours dashed.

interval and reference vector compared to previous composites. At day -4 a convective anomaly is evident over the Andes Mountains near the equator and subsequently moves eastward. Although these OLR anomalies are reminiscent of Liebmann et al.'s (2009) composites of Kelvin wave-like disturbances first appearing over the western Amazon, the associated circulation anomalies are not significant or comparable.

The analogous composite, constructed using OLR anomalies to the east of the base point at day -2 as a 


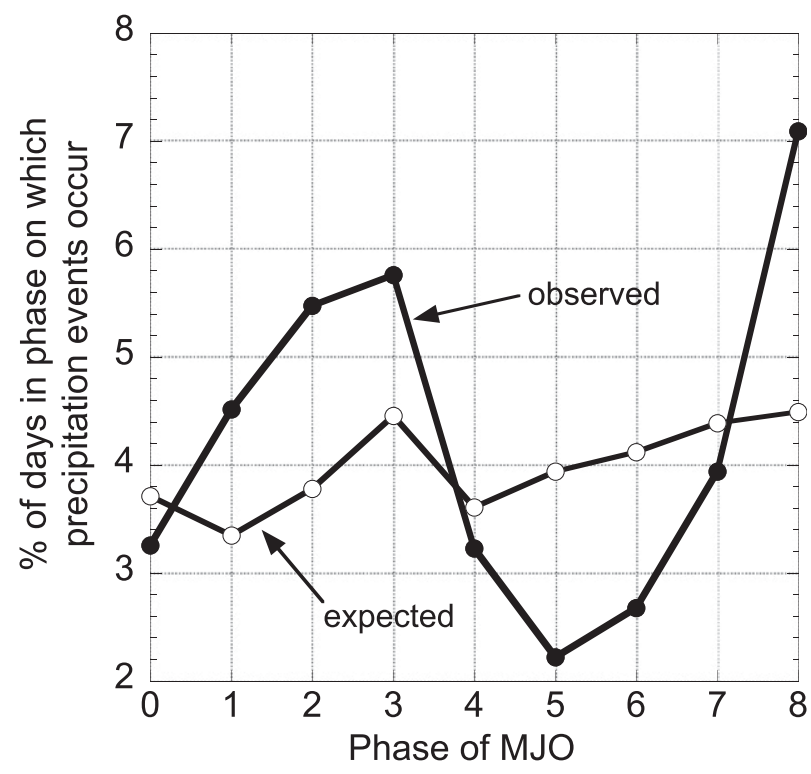

FIG. 17. Percent of days in given phase of MJO on which 2-standard-deviation precipitation events at $5^{\circ} \mathrm{S}, 37.5^{\circ} \mathrm{W}$ occur, indicated by thick curve with filled circles. The thin curve with open circles indicates percent of days expected, calculated by randomization technique described in text. Phase 0 is calculated from all days when MJO is not active.

precursor, is not shown here because the OLR anomaly forms close to the coast and the circulation pattern is not readily interpretable. Although it is commonly believed that disturbances embedded in the Atlantic intertropical convergence zone propagate westward, triggering precipitation in Northeast Brazil (e.g., Ramos 1975), that signal is not apparent here. It is possible that the indistinct composites result from there still being a mixture of forcing mechanisms. For example, 20 of the 102 dates in this last composite are shared by the composite with a Northern Hemisphere precursor, whereas only 2.3 are expected to coincide. Kousky (1979) noted that the westward-moving disturbances identified by Ramos (1975), which have slower phase speeds than tropical disturbances, were also moving equatorward; he suggested that they may not be of tropical origin.

At the coastal grid point there are 384 two-standarddeviation precipitation anomaly events during the 19792005 period. The composite of those events (Fig. 13) includes just 314 dates because only the day with the largest anomalies within a consecutive run of dates is included. A two-standard-deviation event represents $5.7 \mathrm{~mm}$ of anomalous rainfall per day. Of the 314 events, 231 (or $75 \%)$ are included in at least one of the subcomposites (i.e., Figs. 14-16 or the composite using a precursor OLR anomaly east of the base grid point). It is likely that several more events would fit into one of those four categories if the precursor were slightly modified (e.g., a change in the precursor wind direction). Also, if the precursor threshold were lowered, more events would likely be included in each composite, resulting in more of the total rainfall being accounted for by the patterns identified. It is not clear whether the remaining unclassified precipitation events arise from various disparate mechanisms or whether there are other coherent distinct circulation patterns that were missed using the precursor technique.

\section{c. Associations with the Madden-Julian oscillation}

Precipitation throughout the tropics is modulated by the MJO, and indeed the passage of the convectively active phase the MJO is known to be associated with clustering of high daily precipitation events in Northeast Brazil (e.g., Carvalho et al. 2004; Jones et al. 2004). To examine the MJO influence on the large daily precipitation events documented here, these events are binned according to the phase of the MJO. This phase is determined by a multivariate empirical orthogonal function analysis in the tropical sector developed by Jones (2009) and Jones and Carvalho (2011). Composites of OLR for the eight phases of the MJO obtained using this index are quite similar to those computed by Wheeler and Hendon (2004) using somewhat different parameters.

The shaded circles in Fig. 17 show the percent of days with 2-standard-deviation daily precipitation events when the MJO is in each of its phases, with quiescent periods (MJO inactive) indicated by the 0 phase. Phases 1,2 , and 8 are characterized by anomalously low OLR over Northeastern Brazil, while anomalously high OLR is present during phases 4 and 6 . Anomalies are small during phases 3 and 7 . The open circles indicate the percent expected to coincide with each phase, based on the previously described shuffling technique.

The relative occurrence of daily events is largely consistent with the large-scale OLR composite based on MJO phase (cf. Fig. 1 in Jones and Carvalho 2011), with increased frequency of events during phases 8,1 , and 2 and reduced frequency during phases 4-6 (the only dissonance occurs for phase 3 ). The other categories of events (e.g., the coastal point with a precursor) show similar relationships with the phase of the MJO (not shown), with the only inconsistencies found during the transition phases 3 and 7 . The corresponding plot using one-standard-deviation precipitation events is quite similar except for an increase in the percent values in each category (not shown). These results demonstrate a modulation of the high-frequency precipitation events investigated here, likely due to changes in the extratropical and/or tropical basic-state flow associated with the MJO. Further study of this relationship is planned. 


\section{Summary}

Coherent circulation patterns that give rise to precipitation in Northeast Brazil are identified through composite analyses, using high-pass filtered data with a 30-day cutoff. The composite for all extreme events is modified by requiring a precursor criterion to hold, which allows identification of several distinct circulation patterns that do not appear in the full composite. This methodology, however, is necessarily subjective and likely does not isolate all coherent patterns associated with Northeast Brazil precipitation, although it appears to capture the most common of them.

Two locations in Northeast Brazil were selected for this analysis. One is located near the coast, slightly north of Brazil's easternmost point, within the region studied by Hastenrath and his collaborators. The other is situated inland at the point of minimum annual precipitation. At both points precipitation is associated with quasi-stationary midlatitude synoptic wave trains that can originate in either hemisphere, although a low-level cyclone to the south of the precipitation region occurs in both cases. As these waves propagate into the tropics, they encounter a dome of easterlies centered at the equator. Since easterly winds inhibit propagation of nearly stationary waves, this effect may explain the progressively vanishing circulation signal at low levels as the waves propagate equatorward (Fig. 7). Nevertheless, from wave trains originating in the Southern Hemisphere there are substantial signals in temperature and moisture that reflect decaying low-level frontal boundaries associated with precipitation events over the region (Fig. 9), as was found in earlier work by Kousky (1979). We here verify that these boundaries are related to extratropical wave activity propagating into the region. Northern Hemisphere originating wave trains do not exhibit low-level patterns indicative of frontal activity.

Although the present results suggest enhanced precipitation associated with upper-level, equatorwardpropagating cyclonic disturbances (Figs. 6, 7, and 10), we note that Rao et al. (2007) found an inverse relationship between the number of South Atlantic upper-level cyclonic vortices that penetrate close to the equator during the wet season, as determined by Waugh and Polvani (2000), and Northeast Brazil seasonal precipitation. Their argument is that more high-potential vorticity intrusions over the Atlantic result in an anomalous upper-level cyclonic circulation over Northeast Brazil, which promotes upper tropospheric convergence and sinking (Kousky and Gan 1981).

Somewhat surprisingly, in spite of the close proximity of the coastal and interior points and the similarity of the associated composite wave trains, the rainfall dates for each point are nearly independent of each other, for events of both Northern and Southern Hemisphere origin. A high-resolution numerical simulation, however, might reveal salient differences between the two patterns.

For the near-coastal point at $5^{\circ} \mathrm{S}$, OLR precursors appear both east and west of the base point. Those from the east do not seem to be associated with any particular signal, but those from the west can be traced as far west as the eastern flank of the Andes Mountains. In some respects they resemble the coupled Kelvin waves discussed by Wang and $\mathrm{Fu}$ (2007) and Liebmann et al. (2009), although there a strong signature in the circulation pattern is lacking.

The annual cycle peak in the frequency of midlatitude wave trains that can influence Northeast Brazil precipitation occurs during each hemisphere's respective winter season. However, the count of midlatitude wave train events that actually result in Northeast Brazil precipitation is largest during the wet season. Furthermore, only a small fraction of the total wave events result in precipitation anomalies. Therefore we speculate that interannual variability of rainfall is not controlled by year-to-year changes in the number of wave trains impinging on Northeast Brazil but rather is due to meridional variations of the near-stationary trough at that location, as discussed by Hastenrath and collaborators.

During the wet phases of the MJO there is a clustering of large precipitation events, in agreement with previous studies. This relationship implies a modulation of the type of patterns investigated here via changes in the basic-state flow driven by the MJO. We expect a similar clustering to occur during La Niña events, as these tend to be accompanied by enhanced mean precipitation in Northeast Brazil (e.g., Folland et al. 2001). The details of these relationships are currently being investigated.

Acknowledgments. The authors wish to thank NOAA CPO CPPA for partially supporting this research. We also appreciate comments from three anonymous reviewers.

\section{REFERENCES}

Carvalho, L. M. V., C. Jones, and B. Liebmann, 2002: Extreme precipitation events in southeastern South America and large-scale convective patterns in the South Atlantic convergence zone. J. Climate, 15, 2377-2394.

,-- , and -2004 : The South Atlantic convergence zone: Intensity, form, persistence, and relationships with intraseasonal to interannual activity and extreme rainfall. $J$. Climate, 17, 88-108.

De Souza, E. B., and T. Ambrizzi, 2006: Modulation of the intraseasonal rainfall over tropical Brazil by the Madden-Julian oscillation. Int. J. Climatol., 26, 1759-1776. 
_- M. T. Kayano, and T. Ambrizzi, 2005: Intraseasonal and submonthly variability over the eastern Amazon and Northeast Brazil during the autumn rainy season. Theor. Appl. Climatol., 81, 177-191, doi:10.1007/s00704-0040081-4.

Duchon, C. E., 1979: Lanczos filtering in one and two dimensions. J. Appl. Meteor., 18, 1016-1022.

Folland, C. K., A. W. Colman, D. P. Rowell, and M. K. Davey, 2001: Predictability of Northeast Brazil rainfall and real-time forecast skill, 1987-98. J. Climate, 14, 1937-1958.

Garreaud, R. D., 2000: Cold air incursions over subtropical South America: Mean structure and dynamics. Mon. Wea. Rev., 128, 2544-2559.

— latitude air into subtropical and tropical South America. Mon Wea. Rev., 126, 2713-2733.

Gill, A. E., 1980: Some simple solutions for heat-induced tropical circulation. Quart. J. Roy. Meteor. Soc., 106, 447462.

Hastenrath, S., 1990: Prediction of Northeast Brazil rainfall anomalies. J. Climate, 3, 893-904.

_ east Brazil. Quart. J. Roy. Meteor. Soc., 103, 77-92.

— and Eastern Pacific Oceans. University of Wisconsin Press, $117 \mathrm{pp}$.

_ Northeast Brazil rainfall anomalies. J. Geophys. Res., 98, 5093-5102.

— Brazil rainfall anomalies. J. Climate, 6, 743-758.

Hoskins, B. J., and D. J. Karoly, 1981: The steady linear response of a spherical atmosphere to thermal and orographic forcing. J. Atmos. Sci., 38, 1179-1196.

— M. E. McIntyre, and A. W. Robertson, 1985: On the use and significance of isentropic potential vorticity maps. Quart. J. Roy. Meteor. Soc., 111, 877-946.

Hsu, H.-H., 1987: Propagation of low-level circulation features in the vicinity of mountain ranges. Mon. Wea. Rev., 115, 1864 1893.

Jones, C., 2009: A homogeneous stochastic model of the MaddenJulian oscillation. J. Climate, 22, 3270-3288.

—, and L. M. V. Carvalho, 2011: Stochastic simulations of the Madden-Julian oscillation activity. Climate Dyn., in press, doi:10.1007/s00382-009-0660-2.

—, D. E. Waliser, K. M. Lau, and W. Stern, 2004: Global occurrences of extreme precipitation and the Madden-Julian oscillation: Observations and predictability. J. Climate, 17, 4575-4589.

Kalnay, E., and Coauthors, 1996: The NCEP/NCAR 40-Year Reanalysis Project. Bull. Amer. Meteor. Soc., 77, 437-471.

Kidson, J. W., 1991: Intraseasonal variations in the Southern Hemisphere circulation. J. Climate, 4, 939-953.

Kiladis, G. N., 1998: Observations of Rossby waves linked to convection over the eastern tropical Pacific. J. Atmos. Sci., 55, 321339.

—, M. C. Wheeler, P. T. Haertel, K. H. Straub, and P. E. Roundy, 2009: Convectively coupled equatorial waves. Rev. Geophys., 47, RG2003, doi:10.1029/2008RG000266.

Kousky, V. E., 1979: Frontal influences on Northeast Brazil. Mon. Wea. Rev., 107, 1140-1153.

_ east Brazil. J. Meteor. Soc. Japan, 56, 457-465.
— , and N. J. Ferreira, 1981: Interdiurnal surface pressure variations in Brazil: Their spatial distributions, origins, and effects. Mon. Wea. Rev., 109, 1999-2008.

—_, and M. A. Gan, 1981: Upper tropospheric cyclonic vortices in the tropical South Atlantic. Tellus, 33, 538-551.

Kucharski, F., D. Polzin, and S. Hastenrath, 2008: Teleconnection mechanisms of Northeast Brazil droughts: Modeling and empirical evidence. Rev. Bras. Meteor., 23, 115-125.

Liebmann, B., and C. A. Smith, 1996: Description of a complete (interpolated) outgoing longwave radiation dataset. Bull. Amer. Meteor. Soc., 77, 1275-1277.

— America. Bull. Amer. Meteor. Soc., 86, 1567-1570.

— , G. N. Kiladis, J. A. Marengo, T. Ambrizzi, and J. D. Glick, 1999: Submonthly convective variability over South America and the South Atlantic convergence zone. J. Climate, 12, 18771891.

, — , L. M. V. Carvalho, C. Jones, C. S. Vera, I. Bladé, and D. Allured, 2009: Origin of convectively coupled Kelvin waves over South America. J. Climate, 22, 300-315.

Madden, R. A., and P. R. Julian, 1994: Observations of the 40-50day tropical oscillation-A review. Mon. Wea. Rev., 122, 814837.

Molion, L. C. B., and S. O. Bernardo, 2002: Uma revisão da dinâmica das chuvas no nordeste Brasileiro. Rev. Bras. Meteor., 17, 1-10.

Moron, V., A. W. Robertson, M. N. Ward, and P. Camberlin, 2007: Spatial coherence of tropical rainfall at the regional scale. J. Climate, 20, 5244-5263.

Moura, A. D., and J. Shukla, 1981: On the dynamics of droughts in Northeast Brazil: Observations, theory and numerical experiments with a general circulation model. J. Atmos. Sci., 38, 2653-2675.

Ramos, R. P. L., 1975: Precipitation characteristics in the Northeast Brazil dry region. J. Geophys. Res., 80, 1665-1678.

Rao, V. B., and J. P. Bonatti, 1987: On the origin of upper tropospheric cyclonic vortices in the South Atlantic Ocean and adjoining Brazil during the summer. Meteor. Atmos. Phys., 37, $11-16$.

— S. H. Franchito, and T. F. Barbosa, 2007: Impact of high potential vorticity intrusions into the tropical upper troposphere in South Atlantic on precipitation over Northeast Brazil. Geophys. Res. Lett., 34, L06704, doi:10.1029/ 2006GL027873.

Rickenbach, T. M., R. N. Ferreira, J. B. Halverson, D. L. Herdies, and M. A. F. Silva Dias, 2002: Modulation of convection in the southwestern Amazon basin by extratropical stationary fronts. J. Geophys. Res., 107, 8040, doi:10.1029/2000JD000263.

Silva, M. E. S., L. M. V. Carvalho, M. A. F. Silva Dias, and T. Xavier, 2006: Complexity and predictability of daily precipitation in a semi-arid region: An application to Ceará, Brazil. Nonlinear Processes Geophys., 13, 651-659.

Silva Dias, M. A. F., and Coauthors, 2002: A case study of convective organization into precipitating lines in the Southwest Amazon during the WETAMC and TRMM-LBA. J. Geophys. Res., 107, 8078, doi:10.1029/2001JD000375.

Tomas, R. A., and P. J. Webster, 1994: Horizontal and vertical structure of cross-equatorial wave propagation. J. Atmos. Sci., $\mathbf{5 1}, 1417-1430$.

Uvo, C. B., C. A. Repelli, S. E. Zebiak, and Y. Kushnir, 1998: The relationships between tropical Pacific and Atlantic SST and Northeast Brazil monthly precipitation. J. Climate, 11, $551-562$ 
Vera, C. S., and P. K. Vigliarolo, 2000: A diagnostic study of coldair outbreaks over South America. Mon. Wea. Rev., 128, 3-24.

Wang, H., and R. Fu, 2007: The influence of Amazon rainfall on the Atlantic ITCZ through convectively coupled Kelvin waves. J. Climate, 20, 1188-1201.

Waugh, D. W., and L. M. Polvani, 2000: Climatology of intrusions into the tropical upper troposphere. Geophys. Res. Lett., 27, 3857-3860.
Wheeler, M. C., and H. H. Hendon, 2004: An all-season realtime multivariate MJO index: Development of an index for monitoring and prediction. Mon. Wea. Rev., 132, 19171932.

Xavier, T. M. B. S., A. F. S. Xavier, M. A. F. Silva Dias, and P. L. Silva Dias, 2000: A zona de convergência intertropical-ZCIT e suas relações com a chuva no Ceará (1964-1998). Rev. Bras. Meteor., 15, 27-43. 